\title{
COMPACTAÇÃO DO SOLO DEVIDO AO TRÁFEGO DE CARRETAS FLORESTAIS COM DOIS TIPOS DE PNEUS INFLADOS A DIFERENTES PRESSŐES
}

\author{
EZER DIAS DE OLIVEIRA JÚNIOR \\ Engenheiro Florestal
}

Orientador: Prof. Dr. LUIZ ANTONIO BALASTREIRE

Dissertação apresentada à Escola Superior de Agricultura "Luiz de Queiroz", Universidade de São Paulo, para obtenção do título de Mestre em Agronomia, Área de concentração: Máquinas Agrícolas.

PIRACICABA

Estado de São Paulo - Brasil

Setembro - 1998 


\section{Dados Internacionais de Catalogação na Publicação (CIP) DIVISĀO DE BIBLIOTECA E DOCUMENTAÇÃO - Campus "Luiz de Queiroz"/USP}

Oliveira Júnior, Ezer Dias de

Compactaçăo do solo devido ao tráfego de carretas florestais com dois tipos de pneus inflados a diferentes pressōes / Ezer Dias de Oliveira Júnior. - - Piracicaba, 1998.

67 p. : il.

Dissertação (mestrado) - - Escola Superior de Agricultura Luiz de Queiroz, 1998. Bibliografia.

1. Compactação do solo 2. Fisica do solo 3. Madeira 4. Mecanização florestal 5. Pneu 6. Transporte I. Titulo 
"Há tanta gravidade em nada dizer e tudo se entender" Fernando Pessoa 
A minha mãe Cleusa e a minha irmã Emanuela DEDICO

"Mais vale aquilo que se aprende do que aquilo que te ensinam" Ao meu pai Ezer Dias de Oliveira (In Memoriam) OFEREÇO 


\section{AGRADECIMENTOS}

Agradeço primeiramente a Deus por tudo que aprendi durante estes anos.

A ESALQ e a seu fundador Luiz Vicente de Souza Queiroz pela excelência e beleza desta Escola.

A FAPESP pelo auxílio financeiro através da bolsa cedida, a seus consultores pela contribuição ao trabalho e sugestões apresentadas e a Angela Perez e Amália do escritório regional da FAPESP pelos esclarecimentos e cooperação.

Ao Prof. Dr. Luiz Antonio Balastreire pela orientação, ensinamentos, confiança e pelo senso de justiça.

Ao Prof. Dr. Fernando Seixas pela orientação, discussão dos métodos, bem como pela amizade e constantes incentivos.

Ao Prof. Dr. Marcos Milan pelas sugestões, apoio e incentivo.

Aos professores do departamento de Engenharia Rural pelo diálogo e apoio. A RIPASA a qual cedeu a área do experimento e deu o apoio necessário à execução deste trabalho, em nome do Eng. Cláudio Oriani e sua equipe de Avaré, Juarez, Lorival e também ao Eng. Francisco de Assis Ribeiro assessor de pesquisa da RIPASA, pela análise e sinal verde ao projeto. Ao Walter Amabilini da Lençóis Equipamentos pelo esclarecimento técnico. Ao pessoal da empreiteira Riacho pelo apoio e contribuição na realização do experimento em nome de José Antônio, José Carlos e demais operadores. 
Ao Cidão, empresário de visão, preocupado com as questões ambientais o qual não mediu esforços e colaborou para que os pneus e tratores necessários estivessem disponíveis.

Ao pessoal do IPEF do setor de Cultivo Mínimo em nome de Prof. Dr. Leonardo, pelas sugestões, profissionalismo e empréstimo do carro, ao Eng. Roberto, Amarildo, Chico, Ivan e Zé pelo apoio nas reservas do carro. Aos meus ajudantes de campo Everaldo e Aloisio "Luiz" Mariano da Silva pela qualidade e capricho nos trabalhos exaustivos de coleta das amostras. Aos funcionários do departamento de Engenharia Rural Adilson, Afonso, Chicão, Gércio, José Geraldo, Juarez, Juquita, Neide, D. Lurdes e Sandra pelo agradável convívio e troca de informações.

Aos estagiários José Alexandre, Lucy, Ricardo, Rogério e Sidney pelas experiências e práticas de campo.

Aos funcionários da biblioteca, em especial a Eliana pelas correções das referências, a Fátima e Kátia pela atenção dispensada.

Ao Celso do CIAGRI pela ajuda e esclarecimento com as tabelas dinâmicas. Aos compadres Cláudio e Paulinha pela amizade, aventuras compartilhadas e pelo esmero com as cópias e edições finais.

Ao Gilmar do laboratório de propriedades físicas do solo do setor de Irrigação e Drenagem pela valiosa ajuda com as amostras e processamento das análises físicas.

Aos colegas do curso de PG, Alexandre, Atílio, Cristina, Décio, Remi e Rogério pelas discussões, reflexões e principalmente pelo saudável convívio e união, e aos novos colegas Edmilson, Cristina e Juan pela simpatia.

A todos aqueles que direta ou indiretamente contribuíram para a realização deste trabalho, mesmo que não nominalmente citados, mas sempre lembrados pela contribuição e admiração, meus sinceros agradecimentos. 


\section{SUMÁRIO}

Página

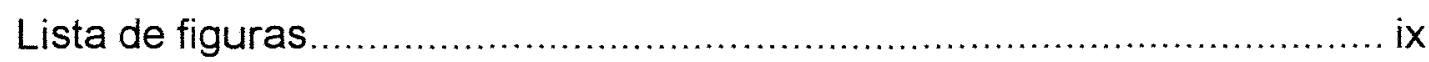

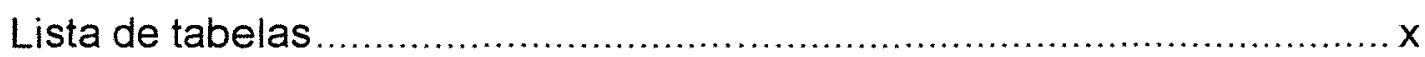

Lista de abreviaturas e símbolos .....................................................

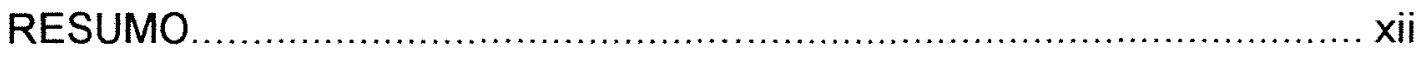

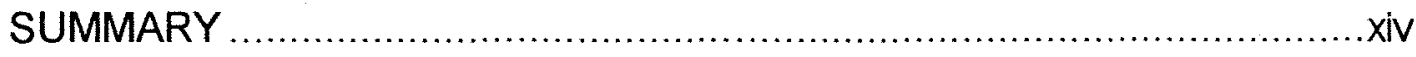

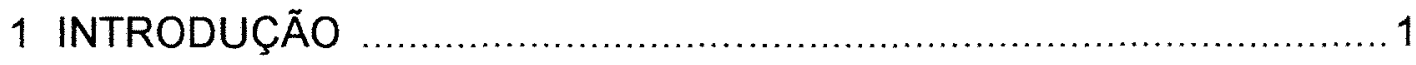

2 REVISÃO DE LITERATURA .................................................. 3

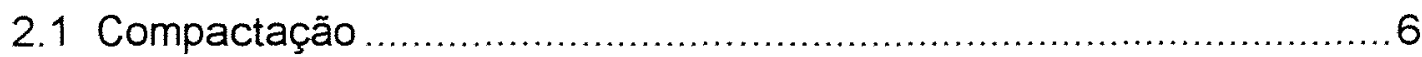

2.2 Fatores de influência na compactação ........................................ 9

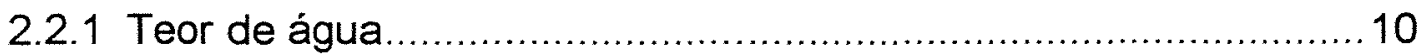

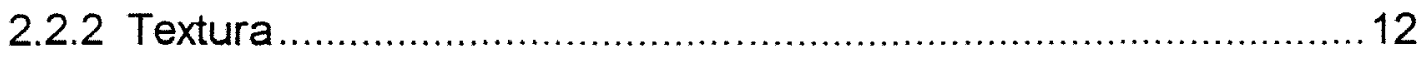

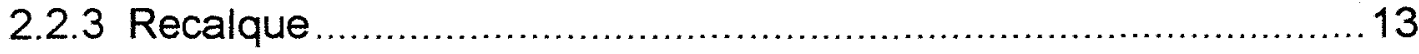

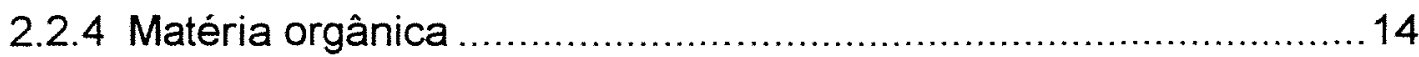

2.2.5 Carga e pressão média de contato ......................................16

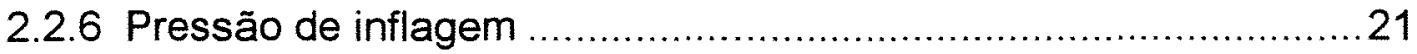

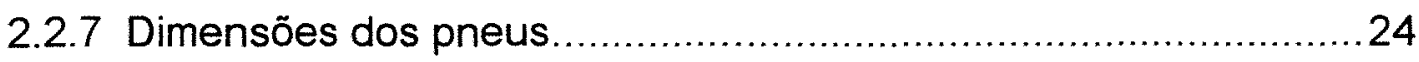

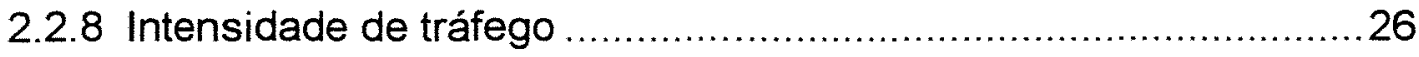


2.3 Dinâmica do Solo ............................................................. 27

2.4 Atenuação dos efeitos da compactação ...................................29

2.5 Estimativa da compactação ...................................................30

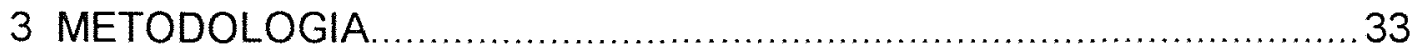

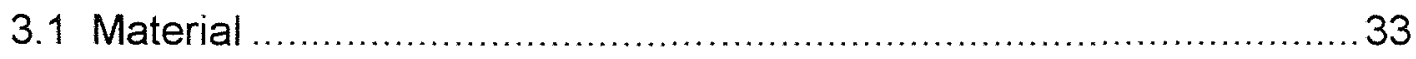

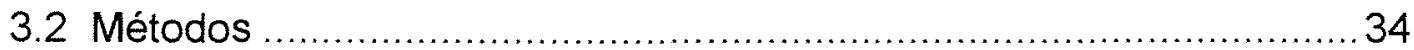

3.2.1 Descrição das operações de colheita da madeira ........................34

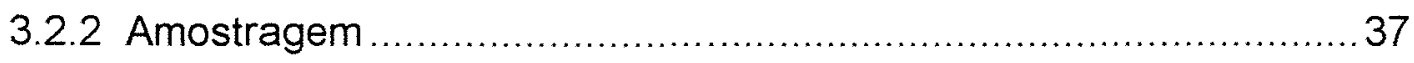

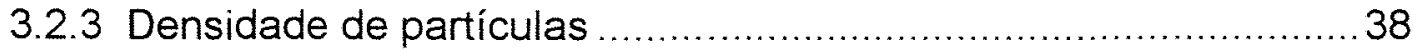

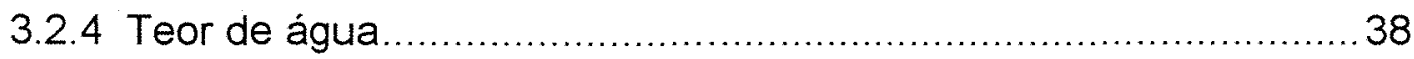

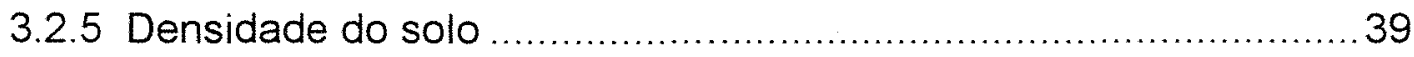

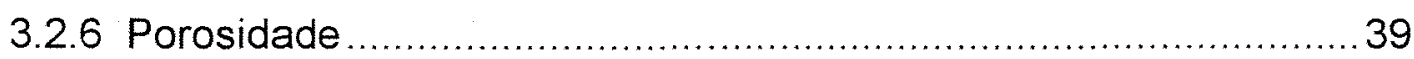

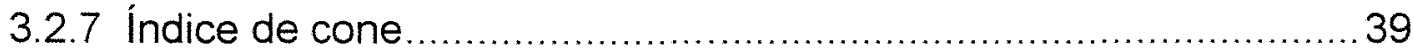

3.3 Instalação do experimento ...................................................... 40

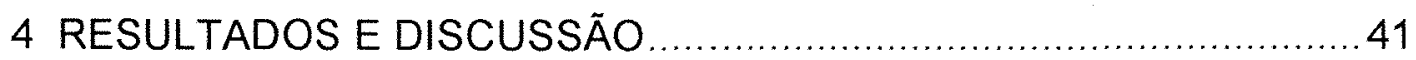

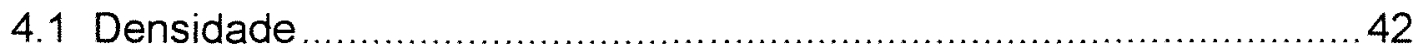

4.1.1 Densidade de partículas ................................................ 42

4.1.2 Densidade do solo .........................................................43

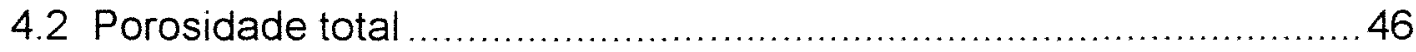

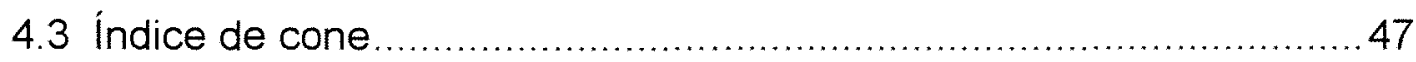

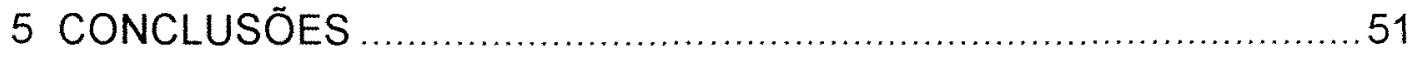

REFERÊNCIAS BIBLIOGRÁFICAS ........................................... 52 


\section{LISTA DE FIGURAS}

Página

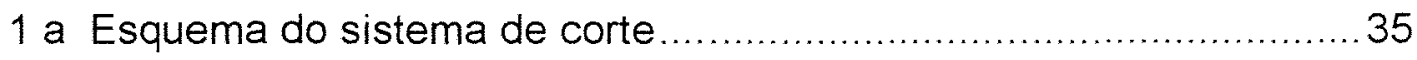

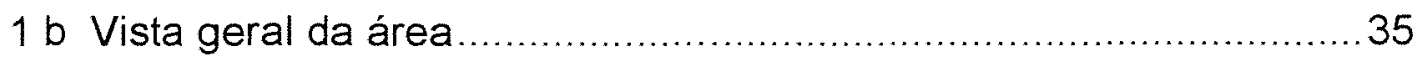

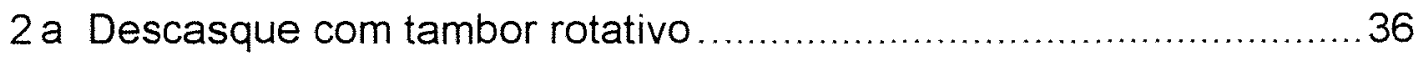

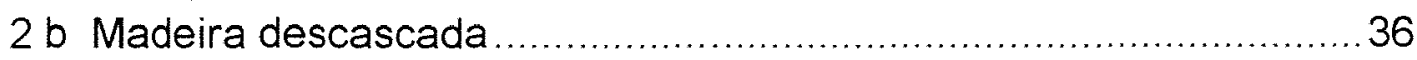

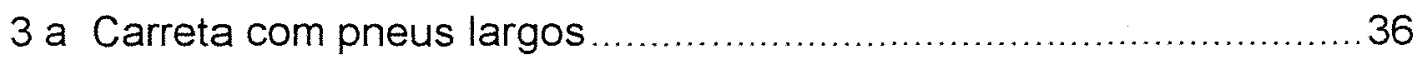

3 b Carreta com pneus estreitos ................................................ 36

4 Curvas médias de índice de cone para os tratamentos ................4 47

5 Variação porcentual dos tratamentos em relação à testemunha ...... 48 


\section{LISTA DE TABELAS}

Página

1 Pressão média de contato para cada tipo de pneu......................41

2 Densidade de partículas para o solo local .................................. 42

3 Média e desvio padrão dos incrementos

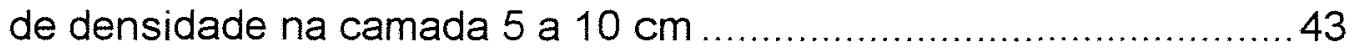

4 ANOVA para o incremento de densidade na camada de 5 a $10 \mathrm{~cm}$.

5 Valores e incrementos médios de densidade para a camada de 5 a $10 \mathrm{~cm}$.

6 Média e desvio padrão dos incrementos de densidade na camada 12,5 a $17,5 \mathrm{~cm}$

7 ANOVA para o incremento de densidade na camada de 12,5 a $17,5 \mathrm{~cm}$.

8 Valores e incrementos médios de densidade para a camada de 12,5 a $17,5 \mathrm{~cm}$.

9 Variações de porosidade nos diferentes tratamentos ....................46

10 Diferenças de indice de cone entre tratamentos por Tukey .............50 


\section{LISTA DE ABREVIATURAS E SÍMBOLOS}

$P$ porosidade do solo (\%)

$\rho_{\mathrm{s}}$ densidade do solo $\left(\mathrm{g} / \mathrm{cm}^{3}\right)$

$\rho_{\mathrm{p}}$ densidade de partículas $\left(\mathrm{g} / \mathrm{cm}^{3}\right)$

$U$ teor de água no solo (\%)

Va. volume do cilindro metálico $\left(\mathrm{g} / \mathrm{cm}^{3}\right)$ st volume de $1 \mathrm{~m}^{3}$ de madeira empilhada $r$ raio do pneumático $(\mathrm{cm})$ 1 largura do pneumático $(\mathrm{cm})$

W Carga aplicada sobre o pneumático $(\mathrm{kN})$ $\mathrm{PC}$ Pressão de contato solo/pneu $(\mathrm{kPa})$ IC Índice de cone (MPa) N. newton

$\mathrm{kN}$ quilonewton n $n^{\circ}$ de impactos necessários para afundar $1 \mathrm{dm}$ 


\title{
COMPACTAÇÃO DO SOLO DEVIDO AO TRÁFEGO DE CARRETAS FLORESTAIS COM DOIS TIPOS DE PNEUS INFLADOS A DIFERENTES PRESSÕES
}

\author{
Autor: EZER DIAS OLIVEIRA JÚNIOR \\ Orientador: LUIZ ANTÔNIO BALASTREIRE
}

\section{RESUMO}

As empresas para se adequarem às normas ambientais e de desenvolvimento sustentável, devem primar pelo bom uso dos recursos solo água - clima. Em conformidade com esta filosofia, este trabalho examina as relações solo - máquina analisando-se os efeitos produzidos no solo, em termos de compactação, pela utilização do equipamento carreta autocarregável na operação de transporte primário das toras. Neste estudo foram considerados os parâmetros índice de cone, densidade, porosidade e teor de água no solo, parâmetros básicos para se determinar a compactação do solo causada por dois tipos de pneus, um estreito com $20 \mathrm{~cm}$ de largura (11.00 - 22") e outro largo com $50 \mathrm{~cm}$ de largura (500/50 - 22.5"), utilizando-se neste último, duas pressões de ar nos pneus. Os resultados de incremento de densidade do solo foram analisados a partir de duas situações distintas, antes da colheita e após o tráfego da carreta. Para a camada de 5 a $10 \mathrm{~cm}$ de profundidade, os incrementos foram de $13 \%$ para o pneu estreito a $455 \mathrm{kPa}$ e $6 \%$ para o pneu largo a $154 \mathrm{kPa}$. 
Foram avaliados também os dados de índice de cone na linha de tráfego e comparados com os dados obtidos na linha não trafegada ao lado.

Os dados obtidos mostraram uma tendência de maior compactação para o pneu estreito, em relação ao pneu largo com diferenças mais pronunciadas a partir de $18 \mathrm{~cm}$ de profundidade abaixo da superfície.

Entre os pneus mais largos, não houve diferença alguma em termos estatísticos para os valores de índice de cone e fica dificil notar qualquer tendência mesmo se analisados os pontos entre 20 e $24 \mathrm{~cm}$. Neste caso o baixo teor de água no solo não possibilitou detectar as possíveis diferenças devido a pressão de ar nos pneus largos. 
SOIL COMPACTION DUE TO TRAFFIC OF A FOREST WAGON WITH TWO TIRE TYPES AT DIFFERENT INFLATION PRESSURES

\author{
Author: EZER DIAS OLIVEIRA JÚNIOR \\ Adviser: LUIZ ANTÔNIO BALASTREIRE
}

\title{
SUMMARY
}

This study determined the impact of two tire options on the soil compaction effects of logging equipment. Tests were done using a standard tractor plus a self loading wagon equipped with narrow or wide tires. The tire configurations differed by a factor of 2 in expected ground pressure. The results were $195 \mathrm{kPa}$ and $88 \mathrm{kPa}$ for the narrow and wide tires respectively.

Two inflation pressures were tested in the wide tires. Despite that, results showed little difference in bulk density, soil strenght, or porosity changes (pre- vs post- traffic) between the two inflation pressures tested for the wide tire.

Considering the moisture conditions encontered in this study for these two tires with their respective ground pressures no fundamental differences were found that would clearly indicate that one tire was better than the other, but the results showed that narrow tires did compact the soil more than wide tires. 


\section{INTRODUÇÃO}

Alguns equipamentos utilizados na colheita de madeira sofrem restrições ao seu emprego em determinadas áreas, em razão da possibilidade de ocorrência de danos significativos ao solo, dentre eles, a compactação, obstrução de drenagem, formação de sulcos e resistência ao desenvolvimento radicular, (Balastreire,1987; Barros \& Novais,1990; Lira Filho,1990; McKee \& Haselton, 1985 e Seixas, 1987).

Os problemas causados pela compactação têm sido uma constante preocupação quando se considera a crescente mecanização associada ao aumento nas capacidades operacionais das máquinas e equipamentos o que normalmente representa um acréscimo das pressões aplicadas numa determinada área, (Fernandes \& Galloway,1987; Hammel,1994; Novak et al,1992 e Voorhees et al., 1978).

Para minimizar os impactos causados pelas operações de colheita da madeira alguns fatores devem ser observados, tais como intensidade do trânsito das máquinas dentro do talhão, manutenção dos resíduos da colheita no local, planejamento das operações e o limite de carga por eixo. No entanto, o dimensionamento correto dos pneus é o item mais diretamente relacionado com a compactação. O uso de pneus adequados é o primeiro passo em direção a um sistema equilibrado visando a sustentabilidade e que pode constar nas cláusulas de prestação de serviço, ou como item de seleção na compra de novas máquinas. 
De acordo com o Anuário Estatístico do Brasil (1996), o setor florestal possui uma área reflorestada de aproximadamente 6,6 milhões de ha, destes 1,43 milhões no setor de papel e celulose.

Segundo Bacha \& Pizzol (1998), o Brasil ocupa hoje a sexta posição entre os produtores mundiais de celulose de fibra curta, com produção de 6,29 milhões de toneladas e importação de apenas 2,24 milhões.

Há uma tendência mundial de preocupação com as questões ambientais, como conseqüência observa-se que toda a cadeia produtiva vem sendo afetada, desde o reflorestamento até o "marketing".

No setor florestal as empresas têm terceirizado algumas das operações de colheita, dentre estas o transporte primário da madeira. A carreta autocarregável é o equipamento amplamente utilizado no transporte das toras, mas que pode ser um dos principais responsáveis pela compactação dependendo do tipo de pneu utilizado.

O principal objetivo deste estudo foi avaliar a compactação produzida pelo tráfego de uma carreta florestal equipada com pneus estreitos comparada aos pneus largos, e testando-se duas pressões de inflagem nos pneus largos. 


\section{REVISÃO DE LITERATURA}

A intensificação da mecanização associada ao uso de máquinas mais pesadas e de maior capacidade operacional nas operações de colheita de madeira, têm sido a principal responsável pela compactação do solo em plantios comerciais. Os danos causados pelo tráfego de máquinas sempre recaem sobre o solo e consequentemente no desenvolvimento das árvores, verificando-se, na maioria dos casos, alterações das propriedades físicas e até mesmo uma degradação no aspecto "qualidade visual" das áreas colhidas pelos diferentes sistemas mecanizados, (Burger et al., 1988; Foltz \& Burroughs, 1991; Gent et al., 1983; Raper et al., 1995; Resinger et al., 1992; Seixas et al., 1995 e Wasterlund, 1994).

Incerti et al. (1987), enfatizaram a necessidade de se quantificar os efeitos e duração da compactação para os vários tipos de solos, de modo a determinar o quanto estes são suscetíveis aos danos produzidos pelos diferentes equipamentos, em uma faixa de umidade na qual as operações são normalmente realizadas.

O conhecimento e entendimento da compactação do solo e suas conseqüências no sistema produtivo é de grande importância para se manejar suas condições físicas de modo a ter-se sustentabilidade da produção e reduzir os custos referentes à energia dispendida posteriormente à colheita, para retornar o solo às condições ideais de desenvolvimento das espécies florestais. 
Embora existam muitas propostas de estudos a respeito de compactação do solo e suas conseqüências na produção agrícola, poucas têm sido as respostas com relação as diversas interações possiveis do tráfego de máquinas e dos efeitos compactantes nas culturas florestais, (Aust et al., 1993; Froehlich, 1977; Greacen \& Sands, 1980; Schafer et al., 1992 Soane et al., 1981 e Voorhees et al., 1978).

A pesquisa deve ter como desafio buscar modelos e ferramentas necessárias ao gerenciamento da compactação levando-se em conta a relação solo - máquina - planta para que se tenha condições de continuar a atividade florestal com um mínimo impacto negativo e custos energéticos, sociais e econômicos viáveis ao longo das gerações.

Quando a colheita é realizada há uma grande movimentação de máquinas, que em condições de baixa umidade e, consequentemente de alta resistência do solo, podem não ocorrer deformações facilmente visiveis, mas podem representar danos potenciais se alguns parâmetros não forem observados, tais como distribuição das cargas aplicadas, esforços aos quais o solo é solicitado, intensidade de tráfego, comprometendo algumas operações subsequentes como as de preparo do solo, (Carter \& Tavernetti, 1968; Gent \& Ballard, 1985; Kreh et al., 1984 e Stransky, 1981).

As propriedades do solo são importantes no sistema produtivo, sendo afetadas pelas operações de campo e pelo sistema mecanizado empregado na colheita. No que diz respeito às condições florestais, principalmente no cultivo do Eucalyptus e Pinus vários autores pesquisaram como se dá a interação solo - planta em termos de compactação, tendo-se verificado algumas restrições nos padrões de crescimento do sistema radicular e da parte aérea, (Davis et al., 1983; Froehlich \& McNabb, 1983; Lockaby \& Vidrine, 1984 e Sands \& Bowen, 1978). 
Segundo Froehlich \& McNabb (1983), podem ocorrer reduções de 5 a $15 \%$ no crescimento de um povoamento florestal em função da compactação produzida pelo trânsito de máquinas. Os efeitos causados podem persistir por vários anos, dependendo das características do local. Concordam neste aspecto Tuttle et al. (1988) e Unger \& Kaspar, (1994), enfatizando que a compactação reduz a penetração das raízes, a aeração e a capacidade de absorção de nutrientes, comprometendo o estabelecimento das mudas. Os autores verificaram que a densidade do solo estava relacionada com qualidade da muda e que para niveis de compactação severa do solo, houve reduções na altura e no sistema radicular das plantas.

De acordo com Froehlich (1977), existem quatro alternativas principais ao se avaliar a compactação do solo e sua interação no sistema produtivo, sendo: (i) determinar o custo real da compactação para os diferentes tipos de solos e espécies florestais, em termos de perdas no crescimento e o valor da madeira, determinando-se o balanço destas perdas; (ii) verificar quais os custos de recuperar as propriedades do solo às condições ideais, por algum método de cultivo; (iii) estabelecer locais de trânsito permanente, mantendo distâncias razoáveis de arraste conforme condições de relevo e volume de madeira a ser retirado e (iv) procurar máquinas cujas caracteristicas ponderais e dimensionais, como pressão de contato com o solo, não tenham impactos negativos sobre a espécie plantada e o solo.

Segundo Wasterlund (1994), o aumento de tráfego de máquinas, é mais crítico quando refere-se à operações dentro dos talhões. Não são somente os danos causados às árvores remanescentes que preocupam, mas os potenciais danos causados às raízes e a compactação do solo produzida pelas máquinas de maior porte. Estas ao trafegarem pelo terreno deixam rastros que são na maior parte, zonas de impedimento ao crescimento das raizes, as quais não têm taxa de elongamento suficiente e acabam confinadas a áreas relativamente pequenas. 
É possível relacionar os danos causados ao solo pelo tráfego de máquinas através de técnicas de predição de resposta do solo sob determinadas condições de carga e transmissão das tensões usando como parâmetros propriedades físicas do solo, umidade e características dos equipamentos, (Afférri,1992 e Langenakens, 1995).

\subsection{Compactação}

De acordo com Chancellor (1977), o volume total de um solo é formado pelo volume de partículas minerais e por poros entre as partículas. É considerado compactado quando a proporção de macropos em relação à porosidade total é inadequada para o eficiente desenvolvimento da planta.

Considera-se a ocorrência de compactação quando há uma redução da macroporosidade (poros $>50 \mu \mathrm{m}$ ) e aumento da densidade, sendo pouco afetados os microporos. Define-se assim compactação como aumento da concentração de massa por deslocamento indiscriminado das partículas a partir de processo mecânico não originário do próprio solo. A compactação envolve um rearranjo e aproximação das particulas sólidas, e consequentemente, um aumento na densidade, (Greacen \& Sands, 1980; Ripoli, 1985 e Seixas, 1996).

A compactação de solos sob culturas agrícolas tem sido muito estudada, e muitas destas pesquisas têm contribuído consideravelmente nas pesquisas com relação as culturas florestais. No entanto, verifica-se algumas características particulares das florestas e plantios comerciais. $O$ corte e arraste de árvores impõe cargas concentradas, além do que a movimentação e processamento das árvores têm sido feitas mais recentemente por máquinas pesadas, causando maiores impactos. As operações florestais não têm um padrão definido como nas culturas agrícolas, e também há uma maior variação e heterogeneidade do grau de compactação e distúrbios, além do que as operações florestais podem comprometer o suprimento e qualidade da água nas áreas de mananciais, (Greacen \& Sands, 1980). 
Schafer et al. (1992), relataram que os estudos de compactação iniciaram-se nos anos 50 e fez uma análise de cinco eventos históricos nesta área a partir de 1960 , os quais tiveram os seguintes pontos discutidos em comum:

(i) compactação é um fenômeno complexo, e as soluções relacionadas a problemas desse tipo não são fáceis de serem encontradas; (ii) compactação deve ser gerenciada, não apenas modificada e (iii) os efeitos nos diversos sistemas produtivos devem ser organizados e incluídos no manejo das culturas, o desenvolvimento de conhecimentos básicos da compactação é necessário para se gerenciar os sistemas. O estudo deve incluir equipes multidiciplinares de engenheiros e pesquisadores. $O$ autor concluiu que 0 grau de compactação desejado para tração difere daqueles para infiltração e crescimento radicular, portanto deve-se manter em níveis compativeis com a cultura instalada e as pesquisas devem enfocar a ação das forças compactantes ao longo do perfil do solo e em profundidade, observando três aspectos básicos:

(i) Propiciar ótima mobilidade e tração para as operações e movimentação das máquinas no campo; (ii) Promover um ótimo desenvolvimento das plantas e (iii) Estabelecer a conservação dos recursos naturais água e solo.

No Brasil algumas das principais pesquisas foram realizadas por Mialhe et al. (1980); Mialhe (1980); Coleti \& Dematê (1982); Milan (1986) e Fernandes \& Galloway (1987), enfocando de modo geral a capacidade de tração, mobilidade, tráfego e seus efeitos nas propriedades físicas do solo.

Recentemente outros autores estudaram alguns fatores associados à compactação, como o caso de Novak et al. (1992), que investigaram o efeito do tráfego e da pressão de contato na compactação. Mantovani et al. (1995), apontaram técnicas viáveis de estimar as forças de tração considerando entre outros fatores a densidade e o teor de água do solo e Seixas (1995), avaliou o tráfego de máquinas na colheita florestal. 
A compactação afeta as propriedades físicas do solo e consequentemente o desenvolvimento das plantas. As propriedades mais seriamente afetadas estão associadas com o teor e transmissão de água, ar, calor, nutrientes, gases e aumento da resistência do solo. Do ponto de vista fisiológico, a compactação afeta o crescimento de plantas devido à redução de volume de macroporos diminuindo a taxa de infiltração e retenção de água, favorecendo o escorrimento superficial e erosão. Pode ocorrer pela redução das trocas gasosas uma diminuição da concentração de oxigênio $\left(\mathrm{O}_{2}\right)$, permitindo que ferro $(\mathrm{Fe})$ e manganês $(\mathrm{Mn})$ passem à formas reduzidas as quais são tóxicas, reduzindo a atividade metabólica e impedindo a entrada de água, uma vez que, para a água entrar 0 ar tem que sair, (Balastreire,1987; Chancellor,1977; Gill \& VanderBerg, 1968 e Ripoli,1985).

A redução da macroporosidade tem, segundo Vomocil e Flocker (1961), como limite inferior, $10 \%$ quando o solo estiver na capacidade de campo. Outros autores também consideram como limite mínimo $10 \%$ de macroporosidade sem o qual a difusão dos gases e os mecanismos de mobilização de nutrientes, (difusão e fluxo de massa) são prejudicados, (Balastreire,1987; Chancellor,1977; Fernandes \& Galloway,1987; Novak et al.,1992; Seixas, 1996 e Voorhes, 1977).

Alguns autores afirmam que a compactação pode ser benéfica em determinadas circunstầncias, como afirmaram Voorhes et al. (1978), ao considerarem que num certo grau pode-se evitar a erosão na entre safra. Alvarenga (1997), considerou que dentro de certo nivel a redução de diâmetro dos poros pela compactação, poderá ser fator favorável ao desenvolvimento vegetal por aumentar a retenção de água.

Balastreire (1987), considera também que se não houver limitações de água e as práticas de manejo fornecerem fertilidade adequada, uma compactação moderada não deve ser 0 fator limitante num sistema produtivo. 
Taylor et al. (1979), afirmaram que compactação por si só não é boa ou má, mas que depende de cada situação. O que se pode verificar é que não há um indice de compactação bem estabelecido para as diferentes culturas

Schafer et al. (1992), afirmaram que as pesquisas devem permitir uma futura relação entre compactação e sua associação com os fatores produtivos, de modo a propiciar uma maneira de manter-se num equilibrio adequado conciliando produção e conservação dos recursos naturais.

\subsection{Fatores de influência da compactação}

A compactação do solo pode ser causada por características naturais, formando camadas mais densas, como movimento discriminado de partículas (argila) por processos pedogenéticos acelerados, que neste caso é classificado como adensamento, (Ripoli, 1985).

Outra forma de compactação pode ocorrer pela reação do solo às pressões e cargas impostas por rodas, esteiras, ferramentas de mobilização e pisoteio de animais, como citam Chancellor (1977) e Gill \& VanderBerg (1968).

De acordo com Barros \& Novais (1990), durante as operações florestais de colheita alguns distúrbios ao solo são comuns. A compactação inicia-se com o corte das árvores e seu impacto na queda, tendo continuidade nas operações subsequentes de colheita.

Froehlich et al. (1980), enfatizaram que a compactação causada pelas máquinas florestais, tinha maior intensidade próximo à superfície e decrescia rapidamente em profundidade, tendo detectado no estudo que a compactação média a $15 \mathrm{~cm}$ de profundidade foi $50 \%$ menor que a $5 \mathrm{~cm}$. 
De acordo com Stone \& Ekwue (1993), a severidade da compactação do solo depende da magnitude e natureza da força compactante, teor de água no solo, textura, densidade inicial do solo, e a quantidade de matéria orgânica incorporada e em cobertura. Os principais fatores envolvidos nesta relação são classificados em duas categorias, sendo uma inerente às características do solo, como teor de água, textura, recalque, quantidade e distribuição de matéria orgânica. A outra refere-se às características das máquinas que podem influenciar na compactação, mencionando-se tipos de rodados, pressão de contato, dimensões dos pneus, pressão de inflagem e intensidade de tráfego.

\subsubsection{Teor de água}

Segundo Mantovani et al. (1995), quanto maior o teor de água mais suscetivel ficará o solo, sendo que a umidade mais critica a favorecer a compactação corresponde aquela faixa próxima da capacidade de campo.

A lubrificação das particulas sólidas pela água favorece o rearranjamento destas, no entanto quando o solo se encontra saturado, pode não ocorrer compactação por uma pressão aplicada num período curto de tempo. Assim, solos com alto teor de água, perto da saturação, estão sujeitos à excessivas tensões de cisalhamento e fluxo plástico e, portanto, menos suscetíveis à redução de poros do que aqueles com teor intermediário. De qualquer forma, altas pressões podem ter efeito compactante se aplicadas num período de tempo prolongado, (Chancellor, 1977).

Aust et al. (1993) constataram que para condições de alto teor de água não houve aumentos significativos da compactação e que a densidade teve variações amortecidas.

Segundo Froehlich (1977), pode-se considerar que a deformação do solo produzida pela primeira passada da máquina em condições de solo úmido, é equivalente aquela produzida após quatro passadas num solo seco. 
Não há dúvidas que é possivel reduzir o grau de compactação, estabelecendo-se niveis de teor de água no solo em que pode-se trafegar com as máquinas. No entanto, segundo o autor, mais importante é determinar os niveis aceitáveis de impacto para cada condição e gerenciálas.

Ohu et al. (1986), mostraram que a incorporação de matéria orgânica alterou o nivel de água do solo, com isso reduziram as tensões de cisalhamento para um mesmo nivel de compactação.

Outro fator influenciado pelo teor de água é a resistência à penetração que segundo Balastreire (1987), aumenta com a compactação, e que para um solo a uma dada densidade, a resistência será maior quanto menor o teor de água existente. Outro fator que influencia esta relação é a distribuição e tamanhos de partículas no solo. $O$ autor ressalta que para solos de textura grosseira (arenosos) o coeficiente de atrito interno aumenta com a compactação para qualquer teor de água no solo.

Seixas (1996), explica que com reduzido teor de água associado com maior densidade no solo a resistência à penetração aumenta consideravelmente.

Voorhes (1977), verificou que um aumento na resistência do solo irá promover um desenvolvimento de raizes finas secundárias, favorecendo a absorção de nutrientes, e concorda neste sentido com os trabalhos realizados por Davis et al. (1983) e Gonçalves (1994), os quais detectaram que para taxas mais elevadas de crescimento das raízes, menor era a densidade de raízes finas, enquanto que as maiores densidades de raízes finas foram encontradas nos sitios de solos menos férteis. Ripoli (1985), advertiu que um aumento excessivo na resistência do solo pode significar enrugamentos e torções nas raízes, dificultando a absorção e translocação da solução nutritiva. 


\subsubsection{Textura}

Segundo Chancellor (1977), a resposta do solo às pressões e tensões de cisalhamento aplicadas, depende da composição granulométrica e estabilidade dos agregados. Solos que contêm uma ampla distribuição de tamanhos de partículas, podem ter os espaços entre os poros maiores preenchidos por partículas menores, e o espaço entre estas, preenchidos novamente por partículas muito finas. As tensões de cisalhamento promovem um aumento de contato entre as partículas, favorecendo o aumento de densidade. $O$ efeito da composição granulométrica na porosidade em que um solo pode ser compactado foi analisado por Bodman \& Constantin (1965) os quais determinaram experimentalmente a compactação máxima, a partir de uma mistura de $80 \%$ de areia com $20 \%$ de silte, na qual se atinge uma proporção menor de porosidade do que se conseguiria com os materiais puros individualmente.

A densidade máxima que um determinado solo pode atingir depende da granulometria, aqueles cuja textura está entre média a grossa e teores de silte menor que $40 \%$, atingem valores mais altos de densidade se comparado aos solos de textura mais fina, os quais devido ao maior volume de microporos não podem ser compactados à densidades mais altas, e por apresentarem proporções de macropos limitantes, (Howard et al., 1981 e Seixas, 1996).

Taylor et al. (1976) testaram pneus diagonais e radiais em sete tipos de solos e em cinco deles o radial apresentou melhor desempenho, justamente nos mais argilosos e texturados, comprovando que são estes também os mais susceptiveis à danos pelo tráfego de máquinas.

Fernandes \& Galloway (1987) verificaram a redução de macroporos $(67 \%$ e $38 \%$ ) e aumento de microporos ( $9 \%$ e $6 \%$ ) para um solo argiloso e arenoso respectivamente, e atribuiram esse efeito diferenciado à diferença textural, sendo que o solo com maior teor de areia, resistiu mais às mudanças estruturais. 


\subsubsection{Recalque}

Segundo Mialhe (1993), recalque é a designação técnica com base no conceito de mecânica do solo. Trata-se do rebaixamento do leito de rolamento pelos rodados, causando uma redução de volume e macroporos, com expulsão do ar e/ou água neles existentes.

O recalque é considerado por muitos autores o sulco formado no trilho do pneu. Pode ser relacionado com mobilidade da máquina, resistência ao rolamento dos pneus e com o grau de compactação, (Chancellor,1977; Mcleod et al., 1966; Taylor et al., 1982 e 1989; VanderBerg \& Gill, 1962; Wästerlund, 1994 e Way et al,1995).

Para McLeod et al. (1966), o recalque é um indicador óbvio da compactação para várias condições de solo. Taylor et al. (1976), encontrou menor recalque nos testes realizados em solo firme e seco.

Segundo Chancellor (1977), a diminuição do volume de poros devida à compactação pelo tráfego de máquinas é aproximadamente igual ao volume do recalque produzido e que os sulcos mais largos resultam em compactação mais superficialmente se comparado aos mais estreitos. O método mais importante para evitar compactação pelo tráfego é restringir o uso de máquinas mais pesadas às condições de solo os quais estejam secos o suficiente de modo a deformarem o mínimo possível. Portanto, utilizandose de máquinas mais leves e pneus mais largos visando a menor compactação é possível remover as camadas compactadas com uso de ferramentas de cultivo convencionais.

Bekker (1960), desenvolveu a partir da equação proposta por Bernstein em 1913, um modelo relacionando a pressão aplicada e o conseqüente recalque. Mais recentemente alguns autores como Adam \& Erbach (1995), têm utilizado este conceito para propor modelos de relação entre recalque e compactação. Estes autores desenvolveram uma equação para relacionar volume de recalque e profundidade de compactação em 
termos do aumento de densidade do solo e validaram a equação com testes em laboratório simulando cargas aplicadas pelas máquinas no campo.

McDonald et al. (1995), verificaram que pneus de mesma largura podem formar diferentes profundidades de recalque se inflados à pressões diferentes, ou seja, pressões de enchimento maiores implicam em maiores profundidades de recalque. Em seu estudo, as configurações que mais causaram recalque do solo foram tanto pneus estreitos quanto largos.

\subsubsection{Matéria orgânica}

A quantidade de matéria orgânica no solo reduz os efeitos da compactação por aumentar a estabilidade dos agregados e por reter parte do teor de água. No entanto, não está claramente definido como a quantidade de matéria orgânica evita a compactação, mas sabe-se que devido à menor densidade das partículas orgânicas estas funcionam como um amortecedor das pressões aplicadas, (Ekwue \& Stone,1995; Ohu et al., 1986 e Stone \& Ekwue, 1993).

Fernandes \& Galloway (1987), verificaram que a redução de porosidade total foi mais acentuada na profundidade de 10 a $20 \mathrm{~cm}$ do que a 0 a $10 \mathrm{~cm}$, e relacionam esse maior efeito de compactação nessa profundidade com o fato de todo o resíduo orgânico ter sido deixado na superfície, o qual proporcionou um efeito protetor contra o impacto das chuvas, evitou o contato direto do rodado e permitiu a recuperação da estrutura do solo.

Wronski (1990) e Wronski \& Humphreys (1994), concluíram que camadas de resíduos florestais proporcionaram uma redução significativa na formação de sulcos (recalque) e aumento na capacidade de suporte do solo. Para cada $10 \mathrm{~kg} / \mathrm{m}^{2}$ de resíduo, colocados sobre outros $10 \mathrm{~kg} / \mathrm{m}^{2}$, houve um aumento na resistência do solo e dias úteis de trabalho em torno de $25 \%$. 
McMahon \& Evanson (1994), estudaram o efeito de diferentes porcentagens de cobertura vegetal na redução da compactação do solo pelo tráfego de um "forwarder" em solo areno-siltoso. Utilizaram como cobertura material de desbaste de pinus e adicionaram nas parcelas camadas na proporção de $20 \mathrm{~cm}$ e $40 \mathrm{~cm}$ sendo comparadas às parcelas de controle. Concluíram que a cobertura vegetal reduziu o grau de compactação causado pelo tráfego da máquina, tendo menores incrementos de densidade do solo nas parcelas cobertas com maior porcentagem de material vegetal. Mesmo assim, detectaram incrementos de densidade na ordem de 16, 21 e 25\% respectivamente para as parcelas com $20 \mathrm{~cm}, 40 \mathrm{~cm}$ e controle. Os valores encontrados não foram significativamente diferentes, mas indicam maior eficiência na redução do grau de compactação causada pela máquina, nas parcelas com maior porcentagem de cobertura vegetal.

Seixas et al. (1995), detectaram reduções significativas na compactação devido ao tráfego de um "forwarder" sobre camada de resíduos da colheita florestal. Coberturas de galhos e acículas na proporção de 10 a $20 \mathrm{~kg} / \mathrm{m}^{2}$ reduziram em média em $40 \%$ o incremento na densidade do solo, se comparado com parcelas sem camada de resíduos.

A presença de residuos da colheita de madeira nas trilhas dentro da floresta servem como elemento atenuante do nivel de compactação do solo devido ao tráfego de máquinas. De acordo com Seixas et al. (1998), a redução média observada no nivel de compactação nos tratamentos com cobertura, medido através da densidade, em relação ao atingido no tráfego em contato direto com o solo foi de $56 \%$. Os autores verificaram que os valores de resistência à penetração registraram uma compactação que pode ser prejudicial ao desenvolvimento das raizes e concluiram que para minimizar os efeitos de compactação o tráfego sobre os residuos da colheita mostrou-se como alternativa viável. Outra alternativa sugerida foi de trocar os pneus veiculares de caminhão que equiparam a carreta, por pneus propriamente florestais, mais largos e com maior área de contato com o solo. 


\subsubsection{Carga e pressão média de contato}

Segundo Mialhe (1993), o primeiro ensaio de pneu num trator agrícola foi realizado em 1932 pelo próprio fabricante, tendo o sucesso desse teste determinado sua produção em escala para tratores. De 1935 a 1946, muitos ensaios de pneus foram realizados nos Estados Unidos, principalmente no Laboratório de Máquinas de Mobilização de Solo, em Auburn, Alabama, mas o efeito dos rodados no solo só passou a ser objeto de estudo na década de 50 .

As pressões exercidas na superfície do solo dependem das características do rodado e do solo. Esta distribuição de pressão, está em função do modo como esta pressão é aplicada na superfície e em menor escala das características físicas do solo, (Chancellor, 1977 e VandenBerg \& Gill,1962).

As pressões normais à superfície de compressão, têm uma tendência de se concentrarem ao redor do eixo vertical abaixo do centro da carga aplicada. Esta tendência é tanto maior quanto maior for a plasticidade do solo devido ao aumento do teor de água, e coesão dependente do teor de argila. Por causa desta tendência, os valores de pressão a $30 \mathrm{~cm}$ abaixo da superfície, podem ser $50 \%$ maior para um solo macio e plástico e $35 \%$ menor para um solo duro e resistente se comparado a um solo normal, (Söhne, 1958).

Gill \& VandenBerg (1968), consideraram que em solo firme o pneu deforma mais que o solo, enquanto que em solos soltos ambos deformam, primeiramente o solo e depois o pneu. Verificaram que para solos arenosos e firmes houve pequena deformação e altos picos de pressão, já para solo solto, houve uma maior deformação, produzindo sulcos profundos, e não ocorreu altos picos de pressão. Os picos de pressão registrados pelas células de carga para solo solto, não representaram as pressões de inflagem dos pneus. As leituras máximas foram obtidas na frente do pneu para solo já 
compactado. Nas laterais do pneu, a variação da tensão se deu pela flexibilidade da carcaça.

Segundo Chancellor (1977), a pressão exercida na superfície é igual ao peso total aplicado dividido pela área de contato entre o solo e o pneu. Cada tipo de rodado aplica uma dada carga de modo particular e com pressão de contato característica. Esta carga pode ser distribuída de diversas formas na superficie, como pneus simples estreitos, pneus duplos, pneus largos de baixa pressão e esteiras. Segundo Soane et al. (1981), a compactação sob os rodados está em função das características dos mesmos, como carga no eixo, dimensões, pressão de inflagem, patinamento, velocidade de deslocamento e número de passadas. Os valores de pressão entre o solo e o pneu podem variar de 1 a 5 vezes a pressão com que o pneu se encontra inflado.

Söhne (1958) e McLeod et al. (1966), afirmaram que, dependendo das características do solo e também do pneu, se for considerado apenas a face lisa do pneu, as forças que atuarão sobre o solo serão menores se comparadas à pressão que as garras exercem. Burt et al. (1990), detectaram que as tensões normais na interface solo - pneu não são uniformes ao longo da seção transversal do pneu e ao longo do perfil do solo. Os valores de pico das pressões normais foram 4 a 5 vezes maiores que a pressão em que o pneu estava inflado. Smith \& Burcham (1994), registraram valores 3,5 a 12,5 vezes maior em seu estudo para pneu especifico para o uso florestal.

Hammel (1994), ao estudar a distribuição das tensões sob pneus com garra do tipo Trelleborg 500 / 60 - 26,5 calibrado a $80 \mathrm{kPa}$ (12 psi) e $19 \mathrm{kN}$ de carga no eixo, determinou a área de contato apenas das garras em superfície rígida considerando a soma das pequenas áreas como a efetiva de contato com o solo. Considerou que as deformações observadas estavam relacionadas com mudanças de propriedades físicas do solo e em função das tensões aplicadas e tempo de ação destas. Os valores de tensão 
máxima atingidos foram da ordem de $108 \mathrm{kPa}$ a $5 \mathrm{~cm}$ e $85 \mathrm{kPa}$ a $25 \mathrm{~cm}$ de profundidade

Segundo Soane et al. (1981), com relação à máquina existem três fatores iniciais que podem ser variados independentemente, que são carga no eixo, dimensão do pneu e pressão de inflagem. Ajustando-se essas variáveis pode-se aumentar ou diminuir a pressão média de contato.

Existem dois aspectos a serem considerados com relação à carga no eixo nos estudos de compactação. O primeiro é a influência da carga na pressão média de contato sobre o padrão de compactação. Com o aumento de carga sobre a roda há a deflexão da carcaça, como uma maneira de manter constante a pressão média de contato, no entanto esta não responde linearmente com a carga e tem ação limitada. O segundo aspecto é que para altas cargas no eixo a reação no solo pode atingir grandes extensões. A pressão em profundidade é determinada pela carga total no eixo, (Chancellor, 1977 e Söhne,1958).

Taylor et al. (1980 e 1989), preocupados com as conseqüências que tratores mais pesados poderiam trazer ao solo em termos de compactação em profundidade, estudaram duas configurações de rodados, um rodado duplo com pneus estreitos convencional de $96,5 \mathrm{~cm}$ de largura e outro rodado simples com pneu mais largo que o convencional com 106,6 cm de largura, solicitados com mesma carga no eixo para duas situações de solo: (a) uma com camada compactada simulando efeitos de aração por anos consecutivos e (b) outra com densidade uniforme ao longo do perfil. Como resultado, encontraram que o rodado com pneu mais largo apresentou superfície de contato $20 \%$ maior, reduzindo desta maneira as pressões sobre o solo. No entanto, a carga no eixo foi o fator de maior influência na compactação em profundidades de 18 a $50 \mathrm{~cm}$. Não houve diferenças significativas das tensões medidas no solo para os dois tipos de rodados, pois não foram afetadas significativamente pela pressão de contato. 
Trabalhos semelhantes foram feitos por outros autores testando várias configurações de pneus e rodados, variando-se a pressão de contato, concluindo que a compactação em profundidade é função primeiramente da carga total aplicada, e em menor grau de influência, da pressão de inflagem dos pneus, assim como da pressão de contato solo - pneu. O aumento da área de contato não diminuiu a compactação considerando-se o perfil em profundidade. $O$ incremento na densidade assim como dos valores de indice de cone foram influenciados pela área de contato evidenciando que o rodado com reduzida pressão de contato compactou em superficie um grande volume de solo, mas em menor intensidade, (Bailey et al.,1993; Erbach \& Knoll, 1992; McDonald et al., 1996; Taylor et al,1976 e 1982).

Bédard et al. (1997), estudaram a compactação produzida pelo uso de carretas com pneus estreitos e largos, bem como eixos duplos e triplos em tandem e concluíram que nenhuma das configurações foi eficiente para minimizar a compactação na situação com carga transportada de $150 \mathrm{kN}$, a situação mais favorável foi a com carga de $95,5 \mathrm{kN}$ e uma pressão de contato de $73 \mathrm{kPa}$.

Mellgren \& Heidersdorf (1984), consideram que a pressão de contato ideal deve estar em torno de $35 \mathrm{kPa}$, e afirmaram que "skidders" com pneus estreitos ultrapassam os $50 \mathrm{kPa}$ mesmo estando vazios, causando um impacto negativo à zona de raízes.

Wood et al. (1990), trabalharam com três diferentes configurações de pneus num trator $4 \times 2 \mathrm{com}$ tração dianteira auxiliar, e mediram as caracteristicas físicas do solo até $50 \mathrm{~cm}$ de profundidade. Foram encontradas mudanças significativas destas características devido à carga no eixo a partir de $25-30 \mathrm{~cm}$. No entanto, o trator com $64 \mathrm{kN}$ de peso, não produziu compactação excessiva se comparado à um veículo de $270 \mathrm{kN}$. Os rodados simples e duplos causaram os mesmos efeitos em profundidade, sendo que para o pneu de alta flutuação não foi detectado efeitos negativos de danos ao solo. 
Wasterlund (1994), afirmou que os danos ocorrem decorrente da pressão exercida pelas máquinas e sua movimentação. De acordo com dados preliminares, os niveis de pressão de contato solo - pneu não devem ultrapassar valores entre 50 a $60 \mathrm{kPa}$, com uma profundidade máxima do sulco de $2,5 \mathrm{~cm}$. Valores acima de $90 \mathrm{kPa}$ são considerados altos pelo autor, que obteve esses valores de acordo com a fórmula:

$$
P c=\frac{W}{r^{* l}}
$$

Onde:

$$
\begin{aligned}
& P c=\text { pressão de contato }(\mathrm{kPa}) \\
& W=\text { carga por roda }(\mathrm{kN}), \\
& r=\text { raio do pneu }(\mathrm{m}) \mathrm{e} \\
& \mathrm{I}=\operatorname{largura} \text { do pneu }(\mathrm{m}) .
\end{aligned}
$$

A fórmula pode ser utilizada, segundo o autor, para fazer comparações entre diferentes configurações de pneus e analisar o potencial de dano que um determinado equipamento possa trazer ao solo. A pressão de contato é a carga distribuída sobre a área de contato solo - pneu, sendo a carga obtida pelos dados ponderais no catálogo da máquina, e a área de contato em função das dimensões do rodado e deflexão da carcaça.

Ainda segundo o mesmo autor, pneus mais largos têm como vantagem melhor distribuição das forças aplicadas ao solo, reduzindo a pressão por área e aumentando a capacidade de tração e de transpor obstáculos. No entanto, apresentam como desvantagem, o maior "arrasto" dos pneus nas curvas, causando maior rompimento de solo. De acordo com Way et al. (1997), pode-se reduzir os efeitos da compactação se forem minimizadas as cargas transportadas e se os pneus forem inflados na pressão correta. 


\subsubsection{Pressão de inflagem}

De acordo com Mialhe (1993), inflagem é o termo técnico para designar a pressão sob a qual o pneu é inflado, sendo o substituto para o termo "pressão de inflação" empregado por alguns fabricantes a partir da tradução "inflation pressure". Entretanto, a palavra "inflação" tem sentido técnico bastante específico em Economia e seu significado léxico não reflete adequadamente a qualificação que se queira dar à uma pressão.

O termo "pressão de inflação" foi utilizado por Lanças \& Upadhyaya (1997) num guia para seleção correta da pressão de ar para pneus radiais.

Seixas (1997), utiliza o termo pressão de insuflagem em trabalho semelhante. Ambos relacionam a pressão de ar nos pneus com a carga aplicada à roda ou lastro adicionado, de modo a estabelecer a pressão correta em que os pneus devem ser calibrados para evitar o efeito compactante. Milan (1986 e 1996), também utilizou o termo pressão de insuflagem em seus trabalhos.

$\mathrm{Na}$ avaliação de impactos da colheita de madeira ao solo, Seixas (1996) utiliza o termo "pressão de inflagem". Assim, tem-se verificado que os termos mais aceitos são pressão de inflagem e pressão de insuflagem, ambos corretos do ponto de vista técnico. Existe a possibilidade do termo "pressão de enchimento" do pneu, mas trata-se de uma designação menos freqüente na literatura.

Sauder (1985), utilizou pneus inflados a 83 e $55 \mathrm{kPa}$ em seu experimento, indicando serem valores possiveis de se trabalhar proporcionando tração, além de conforto ao operador, reduzindo solavancos ao trafegar sem carga.

Calibrar os pneus nas pressões corretas resulta em significativa economia de tempo, dinheiro e minimiza problemas com compactação do solo, além de reduzir os impactos causados pelas irregularidades do terreno, (Upadhyaya \& Lanças, 1994 e Wood \& Mangione, 1992). 
Foltz \& Burroughs (1991), estudaram os efeitos da pressão em que os pneus podem ser calibrados e a quantidade de sedimentos transportados de uma estrada florestal pelas águas da chuva, e chegaram a conclusão de que os pneus calibrados nas pressões mais baixas reduziram a profundidade do sulco no rastro dos caminhões nas condições de alta umidade do solo. A deposição de sedimentos em cursos d'água adjacentes foi em média 2,2 vezes maior para o tratamento com pneus calibrados com pressão mais alta. O estudo indica claramente que 0 uso de pneus calibrados com pressões reduzidas teve reduções significativas dos impactos negativos ao solo.

De acordo com Bailey et al. (1991), os picos de pressão no solo aumentaram proporcionalmente com a pressão de inflagem, sugerindo que esta não deva ser ignorada nos estudos de compactação, sendo mais importante em solos arenosos que em argilosos.

Jones \& Smith (1991) e Upadhyaya \& Lanças (1994), concluiram que utilizando pressões dos pneus a níveis mínimos, de acordo com a carga no eixo, podem-se obter ganhos de tração na ordem de $34 \%$ em solos arenosos e $17 \%$ nos argilosos, com aumento da produtividade, economia de combustivel e significantes reduções de custos e tempo, reduzindo os problemas conseqüentes da compactação do solo.

Wood \& Magione (1992) testaram em práticas de campo, tratores $4 \times 4$ e $4 \times 2$ em mesmas condições de solo, e compararam duas pressões de inflagem nos pneus: $97 \mathrm{kPa}$ (14 psi), recomendado pelo fabricante e $165 \mathrm{kPa}$ (24 psi), normalmente utilizados pelos agricultores americanos. Para o trator $4 \times 4$ com pneus calibrados na pressão correta de $97 \mathrm{kPa}$ (14 psi), se comparado com aquele com pneus calibrados a $165 \mathrm{kPa}(24 \mathrm{psi}$ ), as vantagens foram economia na ordem de $8 \%$ de combustivel e $4 \%$ mais de capacidade operacional em função do menor patinamento. Para tratores $4 \times 2$ as vantagens comparativas foram $26 \%$ mais de economia de combustivel e $11 \%$ mais de capacidade operacional. 
Segundo Wasterlund (1994), a combinação de pneus calibrados com altas pressões, grandes forças de tração e arrasto das rodas aumenta substancialmente os danos ao solo. Estes danos serão tanto maiores quanto maior o teor de água no momento em que as operações estiverem sendo realizadas.

Pode-se verificar que a pressão de ar nos pneus tem maior influência no que se refere aos parâmetros de desempenho tratório (eficiência de tração, patinamento, resistência ao rolamento), economia de combustivel, redução do recalque, conforto ao operador, e minimização dos danos ao solo, que propriamente em efeito compactante, (Bailey et al.,1991; Burt et al.,1982; Goldsack,1988; Jones \& Smith,1991; Lyne et al., 1984; Raper et al.,1995; Taylor \& Burt, 1974 e Wood \& Magione,1992).

A maior pressão de ar nos pneus implica em maiores valores de indice de cone (IC), como verificado por Upadhyaya \& Lanças (1994), que mediu o IC ao lado e na linha de tráfego de um trator $4 \times 4$ em duas profundidades: $0-20 \mathrm{~cm}$ e abaixo de $20 \mathrm{~cm}$. Na profundidade de $0-20 \mathrm{~cm}$, encontrou um aumento no IC de $23,4 \%$ na linha trafegada com pneus na pressão correta de $105 \mathrm{kPa}$ (15 psi) e 119,4\% para a linha trafegada com pneus inflados a $165 \mathrm{kPa}$ (24 psi). Abaixo de $20 \mathrm{~cm}$ não foi detectado aumento de $\mathrm{IC}$ na linha trafegada com pneus na pressão correta e houve aumento de $25 \%$ para a linha trafegada com pneus inflados a $165 \mathrm{kPa}$ (24 psi). A magnitude dos valores de $\mathrm{IC}$ na profundidade de $0-20 \mathrm{~cm}$ variou de 665 a $3500 \mathrm{kPa}(326 \%)$. 


\subsubsection{Dimensões dos pneus}

Já em 1966, preocupados com os efeitos que a compactação poderia causar às culturas agrícolas, McLeod et al. (1966) testaram três configurações básicas, sendo pneus simples, pneu duplo e outro extra largo de baixa pressão, concluindo que em termos de danos ao solo e pressões verticais os que menos causaram compactação foram em ordem crescente o de baixa pressão, pneu duplo e simples.

Uma das práticas mais comuns para reduzir a compactação é o correto dimensionamento dos rodados, de modo a distribuir o peso da máquina sobre uma maior superfície. Aumentando-se o diâmetro elou a largura do pneu, aumenta-se a área de contato. $\mathrm{O}$ aumento em largura não tem necessariamente melhor efeito que o aumento em diâmetro. Áreas de contato estreitas e longas proporcionam, na maioria dos casos, melhor eficiência de mobilidade se comparada à áreas largas e curtas. Assim, aumentando-se o diâmetro de uma roda tem-se maior eficiência, mas este aumento é limitado por questões dimensionais dos equipamentos e de estabilidade, (Mellgren \& Heidersdorf, 1984 e Sauder, 1985).

Muitas pesquisas têm sido conduzidas com o objetivo de analisar quais os efeitos que pneus de dimensões diferentes podem causar e a relação com compactação do solo. Klaas (1988), enfocou que os pneus específicos para uso florestal têm apresentado rápida evolução e melhoraram em $60 \%$ no que tange à resistência à perfuração por farpas nas laterais dos pneus, proporcionando maior confiabilidade ao conjunto rodante e evitando-se paradas freqüentes para manutenção. Ainda segundo $\circ$ autor a área de contato solo - pneu para os mais largos é de $3057 \mathrm{~cm}^{2}$ contra $2257 \mathrm{~cm}^{2}$ dos convencionais, sem com isso representar aumento excessivo na bitola total do trator, se comparado com a opção de rodados duplos. 
O primeiro ponto unânime entre os autores é que pneus radiais são superiores no que se refere à máxima capacidade de tração com mínimos impactos ao solo e ao operador, (McLeod et al., 1966; Taylor et al., 1976; Upadhyaya \& Lanças, 1994 e Wood et al., 1990).

No setor florestal os testes de pneus especialmente mais largos começaram na década de 80 , no Canadá, em função dos distúrbios ocasionados no solo pelo uso dos pneus estreitos. O uso desses pneus mais largos denominados por ultra baixa pressão, baixa pressão \& alta flutuação tem como proposta diminuir o recalque e danos ao solo, além de, com a menor pressão de inflagem, aumentar a área de contato, estabilidade da máquina e produtividade, (Mellgren \& Heidersdorf, 1984; Sauder,1985 e Yong, 1992).

Mellgren \& Heidersdorf (1984) relataram testes comparativos entre pneus estreitos e pneus de alta flutuação feitos durante quatro anos para as condições de solo frágil e úmido no verão canadense e encontraram muitas vantagens a favor dos pneus mais largos, incluindo aumentos de produtividade na ordem de $60 \%$, redução de $40 \%$ no consumo de combustível e menores danos ao solo. Um trabalho comparativo entre pneu convencional e alta flutuação de 62 e $76 \mathrm{~cm}$ de largura respectivamente com $36,5 \mathrm{kN}$ de carga no eixo, mostrou que o mais largo teve uma área de contato $22 \%$ maior reduzindo significativamente as pressões na superficie em relação ao convencional, mas as pressões foram iguais de 18 a $50 \mathrm{~cm}$ de profundidade, (Taylor \& Burt, 1984).

Yong (1992), fez um levantamento de campo detalhado comparando pneus largos com pneu estreito no período de 88 a 90 . Os dados revelaram 9 a $12 \%$ mais de produtividade e $50 \%$ menos de distúrbio ao solo com o uso de pneus mais largos nas condições de alto teor de água no verão. 


\subsubsection{Intensidade de tráfego}

As principais forças causadoras da compactação em solo sob culturas florestais originam-se pelo tráfego das máquinas utilizadas nas atividades de manejo e colheita da madeira, como cita Seixas (1996). Essas pressões aplicadas sobre a superfície do solo são distribuídas ao longo do perfil em função das tensões e deformações em maior ou menor escala de acordo com as características físicas do solo, (Gill \& VanderBerg, 1968).

Como a reação do solo é diferenciada para intensidade e duração da pressão aplicada, a primeira passada é a que ocasiona a maior parte dos distúrbios ao solo, no entanto este impacto irá depender das condições iniciais do solo e sua resistência. Solos soltos terão maiores incrementos de densidade do que solos firmes. (Soane et al.,1981)

Jakobsen (1993), verificou que os efeitos do tráfego de máquinas numa floresta de eucaliptos foram detectados 32 anos após a última intervenção. Os dados mostraram que os valores de densidade do solo nas áreas trafegadas foram estatisticamente superiores aos obtidos na área não trafegada considerando-se a camada de 0 a $30 \mathrm{~cm}$ de profundidade.

Um pneu diagonal com medidas $345 \times 965 \mathrm{~mm}\left(13.6 \times 38^{\prime \prime}\right) \mathrm{e}$ calibrado na pressão de $152 \mathrm{kPa}$ (22 psi) foi testado em três tipos de solo solto passando-se no mesmo local quatro vezes e medindo-se a tração e mudanças das propriedades físicas destes solos. Concluiu-se que $75 \%$ do incremento total de densidade ocorreu na primeira passada da roda, (Taylor et al., 1982).

De acordo com Froelich (1980), pelo menos $60 \%$ do aumento máximo ocorrido para a densidade em uma trilha, cujo tráfego superou vinte passadas, ocorreram com as primeiras 6 passadas. $O$ incremento médio de densidade a $20 \mathrm{~cm}$ de profundidade, variou de 9 a $16 \%$. 
Coleti \& Demattê (1982), verificaram que a tendência dos valores de densidade do solo é aumentar com a intensidade do tráfego, sendo que aproximadamente 50 a $60 \%$ da compactação do solo se manifestaram com as primeiras passadas e portanto deve-se evitar tráfego desnecessário dentro do talhão. Outros autores também verificaram este comportamento do tráfego e seus efeitos cumulativos na compactação, concluindo-se de modo geral que a maior parte da compactação total em uma trilha de arraste ocorre nas primeiras passadas de uma máquina, (Froehlich \& McNabb, 1983; Hatchell, 1970; Koger et al., 1985).

Burger et al. (1988) e Aust et al. (1993), em seus estudos, compararam os efeitos de tamanho dos pneus e intensidade de tráfego nas propriedades físicas do solo, e concluíram que a intensidade de tráfego teve maior influência que o tamanho de pneus.

Aust et al. (1993), avaliaram o impacto causado ao solo por sete tipos de pneus em quatro niveis de tráfego, $0,1,3$ e 7 passadas. $\mathrm{Na}$ condição de umidade próxima a capacidade de campo não foi detectado grandes vantagens para os pneus mais largos. Entretanto, constataram que houve um aumento proporcional dos distúrbios ao solo com o aumento do nivel de tráfego, sendo a primeira passada a que provocou maior variação de densidade do solo, concluindo-se então que o fator de maior influência foi o nivel de tráfego.

\subsection{Dinâmica do Solo}

A distribuição e magnitude das pressões e tensões de cisalhamento sobre uma área de contato estabelece a capacidade de um rodado para desenvolver máxima tração com mínima compactação do solo. Para melhor conhecimento dos fatores que afetam a distribuição de tensões são necessários os conceitos de Dinâmica do Solo, (VanderBerg \& Gill, 1962). 
A Dinâmica do Solo pode ser definida como a relação entre forças que são aplicadas e a reação do solo, essa reação é associada às tensões no solo e sua distribuição.

O início dos estudos de Dinâmica do Solo ocorreu com uma tese nos Estados Unidos de E.A.White em 1918 sobre a ação de um arado e a partir de 1920 começaram os trabalhos nesta área especificamente. Mas somente após 1930, e a partir da Segunda Guerra Mundial, é que os trabalhos tiveram maior ênfase e finalmente a partir de 1950, juntamente com os estudos sobre pneus, a Dinâmica do Solo se firmou como área de pesquisa e foram feitas as primeiras padronizações de metodologias entre os diversos centros de pesquisa, (Balastreire,1987 e Gill \& VanderBerg,1968).

Os conceitos de tensão e deformação são fundamentais, juntamente com as teorias de elasticidade e plasticidade, originadas no campo da Resistência dos Materiais e utilizadas na Dinâmica do Solo, para se estabelecer as bases teóricas dos fenômenos de reação do solo às pressões impostas, como no caso dos rodados das máquinas, (Mialhe,1993).

A primeira aproximação do modelo de distribuição das tensões segundo Gill \& VanderBerg (1968), foi feita com um sistema de equação diferencial por Boussinesq em 1885, considerando uma carga pontual vertical. O solo foi idealizado como isotrópico e elástico de acordo com a lei de Hooke e no entanto a descrição não foi satisfatória para o solo com sua variação natural do teor de água e densidade. Isto levou Fröhlich em 1934 a introduzir um fator de concentração considerando-se o grau de resistência do solo, que também em condiçōes de campo não representou o comportamento real do solo, mas tem sido muito utilizado como base para modelos mais atuais, que podem ser associados com o uso do método de elementos finitos para determinar o comportamento do solo, (Hammel, 1994).

Dwyer \& Heigo (1984), ao testarem pneus de diferentes medidas, verificaram que o modelo para predizer o comportamento dos pneus baseado no IC (índice de cone), não foi satisfatório para os pneus largos. Segundo os 
autores, o modelo deve ter sido proposto inicialmente para uma relação largura/diâmetro dos pneus tradicionais.

\subsection{Atenuação dos efeitos da compactação}

Diversas medidas para atenuar e até prevenir os efeitos nocivos da compactação têm sido sugeridas, como: aumento do diâmetro e largura dos pneus, rodados duplos, melhor distribuição do peso da máquina, redução da pressão de contato solo - pneu, menor pressão de ar no pneu, restrição de tráfego em áreas úmidas e trafegar sobre camada de resíduos (casca e galhos), (Burger et al.,1988; Ekwue \& Stone,1995; Lanças \& Upadhyaya, 1997; Raghavan et al.,1995; Seixas et al.,1995; Seixas,1997; Stone \& Ekwue,1993 e VandenBerg \& Gill, 1962).

Burger et al. (1988) e Aust et al. (1995) enfatizaram que o uso de pneus largos não pode ser o único meio de evitar degradação do solo, pneus largos podem promover dependendo do caso, aumento de produtividade e redução dos distúrbios na superfície do solo, mas não elimina a necessidade de se fazer um estudo detalhado de impacto ambiental e planificação antes da colheita para a área em questão.

Pneus mais largos são indicados por Aust et al. (1995) para minimizar a compactação do solo, concluindo que a vantagem de um pneu de $127 \mathrm{~cm}$ de largura sobre pneu estreito foi devido à maior área de contato, resultando menor influência na densidade e na porosidade do solo. Afirma no entanto ser importante o dimensionamento de máquinas ao sistema utilizado.

Yong (1992), ao comparar pneus largos com estreitos, concluiu que pneus mais largos proporcionam, entre outras vantagens, maior conforto, segurança e maior alcance nas áreas de difícil acesso, as quais considerou suficientes para se adota-los como superiores para as operações florestais. Com menor distúrbio ao solo o autor considerou ainda, que menor serão os problemas com compactação, erosão e degradação ambiental. Maiores serão as vantagens quanto mais limitantes forem as condições de colheita. 
Segundo Sauder (1985), deve-se programar as operações, planejar a locação dos carreadores, e treinar os operadores, para minimizar os impactos ambientais. Deve-se levar em conta as operações subsequentes à colheita, como preparo especial do solo nas linhas trafegadas. O autor afirma ainda, que os cuidados para minimizar os impactos ambientais da colheita devem ser observados testando-se quais os impactos causados pelos diferentes sistemas, buscando configurações de máquinas e pneus que evitem danos ao solo.

Schilling (1993) ressalta que todos os avanços tecnológicos de máquinas e pneus para evitar impactos ambientais negativos e conduzir as florestas com bom crescimento, serão em vão se não for considerada a questão de treinamento e conscientização dos operadores.

\subsection{Estimativa da compactação}

Compactação pode ser estimada por diversos parâmetros, no entanto todos são indiretos como porosidade, condutividade hidráulica, infiltração, resistência à penetração e densidade do solo, (Balastreire,1987; Chancellor, 1977 e Gracen \& Sands, 1980).

McLeod et al. (1966), utilizaram densidade e resistência à penetração verificando os efeitos comparativos destes parâmetros com as pressões aplicadas e seus efeitos em profundidade, no entanto encontraram uma variabilidade muito alta dos valores de densidade e não a relacionaram com os demais parâmetros. Taylor \& Burt (1974), coletaram amostras a $5 \mathrm{~cm}$ de profundidade no rastro de três tipos de rodados, em caixas de solo para teste em condições controladas, verificaram que a densidade do solo teve incrementos maiores no rastro de pneu convencional que para esteiras em todas as condições testadas. 
Muitos autores têm utilizado como principais parâmetros, principalmente a densidade do solo e o índice de cone ao avaliarem o efeito compactante de tipos e dimensões de pneus e niveis de tráfego, (Bailey et al., 1993; Erbach \& Knoll, 1992; Novak et al., 1992; Perumpral, 1987; Raper et al., 1995; Seixas et al., 1995 e Wood et al., 1990).

Daniel et al. (1993), encontraram comportamento diferenciado do solo em termos de resistência à penetração em diferentes locais (com tráfego, entre tráfego e sem tráfego) mostrando que a resistência à penetração foi maior nos locais com tráfego e menor onde não houve a passagem dos pneus. Concluem que a resistência à penetração mostrou ser um parâmetro considerável ao se mensurar camadas compactadas no controle de tráfego.

Segundo Stolf (1990), os dados do penetrômetro de impacto podem ser expressos em impactos $/ \mathrm{dm}$ ou $\mathrm{kgf} / \mathrm{cm}^{2}$. Porém, a variável impacto / $\mathrm{dm}$ não é uma unidade de resistência, e sim de condutância função inversa da resistência, não sendo possivel manipulá-la (média, análise estatística etc.). É necessário fazer-se a conversão através de alguma fórmula. Sendo assim, - autor, no que se refere ao tipo de penetrômetro a ser utilizado na avaliação de resistência à penetração de um determinado solo, avaliou as quatro principais fórmulas empregadas na engenharia civil para transformação dos dados de penetrômetro de impacto ( $n^{\circ}$ de impactos / penetração) em força por unidade de área: a de Sanders, a dos holandeses, a de Brix e a dos holandeses modificada e comparou com os dados obtidos com 0 penetrômetro convencional de mola. O autor variou no teste a massa de impacto do penetrômetro, a granulometria e dureza do solo.

Ainda segundo o autor, as fórmulas de Sanders, de Brix e a dos holandeses têm como objetivo determinar a resistência dinâmica do solo, ou seja, a resistência média que efetivamente a ponta de penetração encontra no seu rápido avanço característico dos penetrômetros de impacto. 
A diferença entre a resistência dinâmica da estática (penetrômetro convencional de mola) aumenta com a resistência e elasticidade do solo. Assim, a melhor fórmula é aquela que gera valores de resistência dinâmica próximos aos da estática em solo arenoso e também em solo argiloso, devendo ser praticamente constantes, independente da massa de impacto adotada. Concluiu que a melhor fórmula de conversão para estimativa do indice de cone é a dos holandeses.

A variabilidade espacial das propriedades físicas do solo é um sério problema na análise e interpretação dos dados de índice de cone, este parâmetro requer alto número de repetições e deve estar associado com o teor de água no solo no momento das medições, (Ayers \& Perumpral, 1982; Perumpral, 1987 e Yasin et al., 1993).

Diferenças de densidade foram usadas por Adam \& Erbarch (1995) para determinar a profundidade em que as pressões aplicadas causaram compactação significativa. Também Way (1995), ao testar pneus com diferentes horas de uso utilizou densidade e resistência à penetração para avaliar estas diferenças, verificando que para solo arenoso o pneu meia vida proporcionou aumentos significativos de densidade em relação aos demais.

De acordo com King \& Haines (1979), o incremento na densidade do solo é maior próximo da superfície e menor abaixo dos $20 \mathrm{~cm}$ de profundidade.

Fenner (1996) ao comparar a intensidade de danos às propriedades físicas do solo decorrentes do tráfego de máquinas durante a extração da madeira, também utilizou como parâmetros densidade do solo e resistência à penetração. $O$ trabalho relata aumento de resistência nos primeiros $20 \mathrm{~cm}$ de profundidade e aumento da densidade de $0,15 \mathrm{~g} / \mathrm{cm}^{3}$ após nove passagens da máquina. 


\section{METODOLOGIA}

\subsection{Material}

Neste trabalho foi utilizado um equipamento denominado trator auto carregável (T.A.) composto por trator agricola $4 \times 2$ com tração dianteira auxiliar (t.d.a.) com cerca de $80 \mathrm{~kW}$ de potência e carreta de dois eixos em tandem com grua para carregamento

A carreta foi equipada com dois tipos de pneus, primeiramente o estreito com $20 \mathrm{~cm}$ de largura (11.00 - 22") e depois o largo com $50 \mathrm{~cm}$ de largura (500/50-22.5").

Martelo deslizante "AMS" para amostras indeformadas de solo, anéis metálicos, tampas plásticas, canetas para retroprojetor, pá, canivete. penetrômetro de impacto, estufa para secagem das amostras, balança. sacos de papel e bandejas.

\section{Descrição da área}

Para realização do presente estudo foi escolhido um plantio comercial de Eucalyptus grandis no municipio de Botucatu, Estado de São Paulo, Latitude $22^{\circ} 56^{\prime}$ e Longitude $48^{\circ} 27^{\prime}$.

O clima da região é classificado, de acordo com Köppen, como sendo do tipo Cfa. O tipo Cfa é mesotérmico. de inverno seco, com temperatura média do mês mais frio (julho) inferior a $18^{\circ} \mathrm{C}$, a do mês mais quente (janeiro) superior a $22^{\circ} \mathrm{C}$ e o total de chuvas do mês mais seco ultrapassa $30 \mathrm{~mm}$. A precipitação média da área é de $1430 \mathrm{~mm}$ por ano. 
O tipo de solo é $A Q$ areia quartzosa de origem sedimentária, relevo local suave ondulado e, a composição granulométrica do solo nas parcelas, de acordo com a análise textural, em média é composto por $81,47 \%$ de areia, $4,74 \%$ de silte e $13,78 \%$ de argila. A classificação do solo está de acordo com as normas apresentadas por Camargo et al. (1987).

O povoamento de Eucalyptus grandis encontrava-se na fase de segundo corte, espaçamento inicial de $3,0 \times 1,5 \mathrm{~m}$ e com cepas variando de 12 a $25 \mathrm{~cm}$ de altura. As parcelas experimentais foram instaladas em abril de 1997.

A variação da quantidade e distribuição irregular do residuo existente nas parcelas, poderiam ser fatores de variação indesejável nos tratamentos. Não sendo esta, objeto principal de estudo e visando maior controle local, foi realizado o experimento apenas na condição sem camada de resíduo.

\subsection{Métodos}

\subsubsection{Descrição das operações de colheita da madeira}

As operações de colheita podem ser divididas em três etapas fundamentais, sendo: corte, descasque e transporte. Cada uma delas foi realizada por empresas diferentes de prestação de serviço.

As árvores foram cortadas com motosserras em toras de $2,4 \mathrm{~m}$, descascadas mecanicamente e dispostas em faixas ao longo do talhão. $O$ transporte primário foi efetuado após duas semanas para que o excesso de água fosse removido, reduzindo-se desta maneira a carga transportada por viagem. 
Corte: compreende também o desgalhe e traçamento. O conjunto de quatro linhas de árvores é denominado "eito" de corte, onde o operador de motosserra corta as árvores das linhas 1 e 4 , direcionando-as de modo a distribuir a galhada na "rua" central do eito, entre as linhas 2 e 3.

Nas linhas 2 e 3 as árvores são cortadas e direcionadas para cada rua dos "eitos" adjacentes. (Figura 1)

Formam-se desta maneira ruas de madeira e de galhos alternadas.

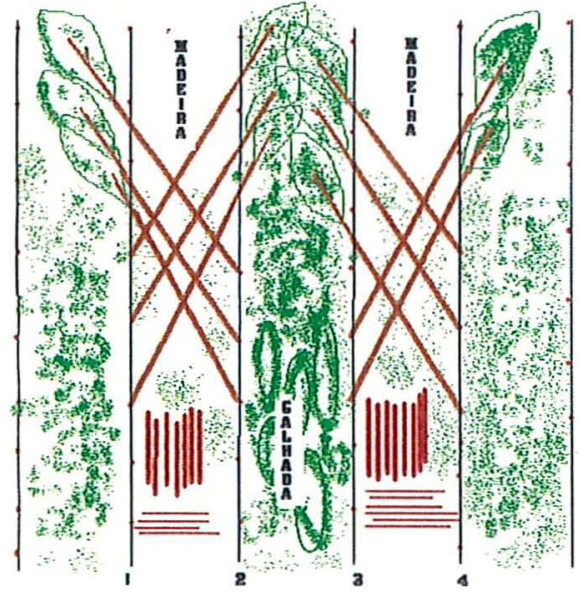

(a)

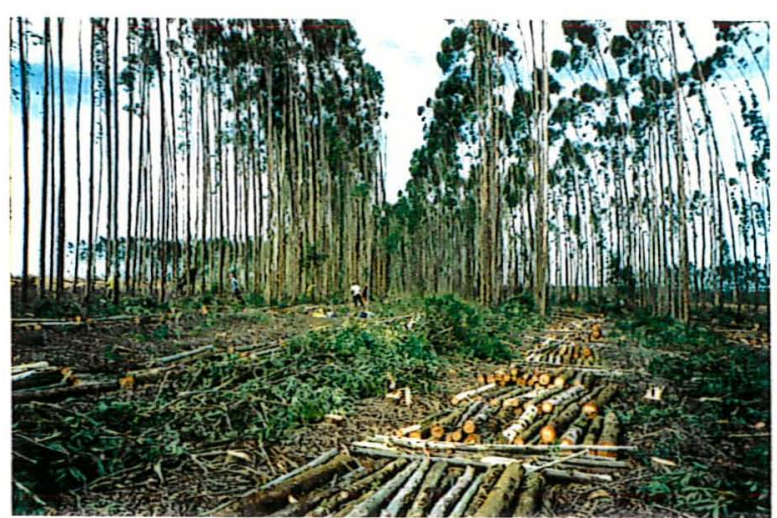

(b)

Figura 1: Esquema do sistema de corte (a) e vista geral da área (b) 
Descasque: realizado por um descascador de tambor rotativo acoplado a um trator agrícola, cuja operação foi descascar toda a madeira destinada à celulose e movê-la para um dos lados do eito, deixando-a separada da madeira mais fina. (Figura 2)

Transporte: a finalidade é remover toda a madeira de dentro dos talhões e depositá-la em pilhas ao longo dos carreadores. Essa operação, chamada de remoção, é realizada pelo trator auto carregável, sendo este equipamento utilizado no estudo. (Figura 3)

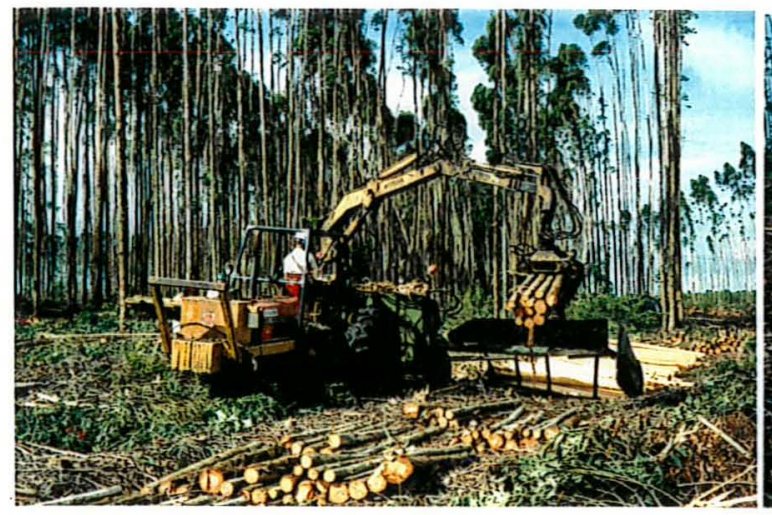

(a)

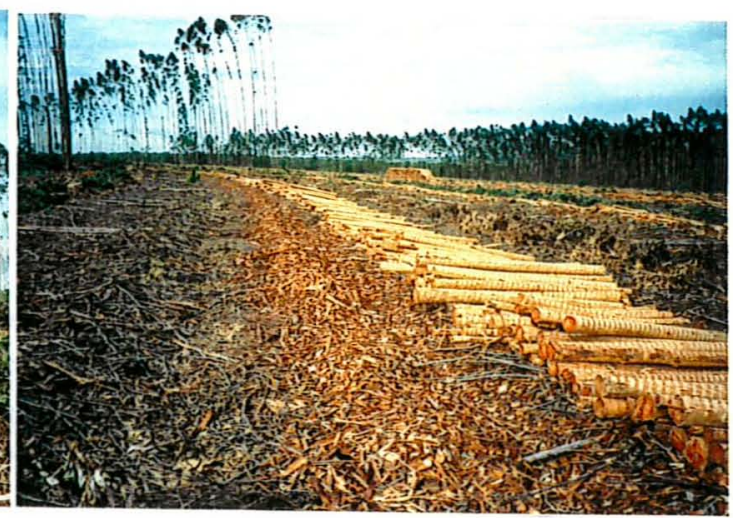

(b)

Figura 2: Descasque com tambor rotativo (a) e madeira descascada (b)

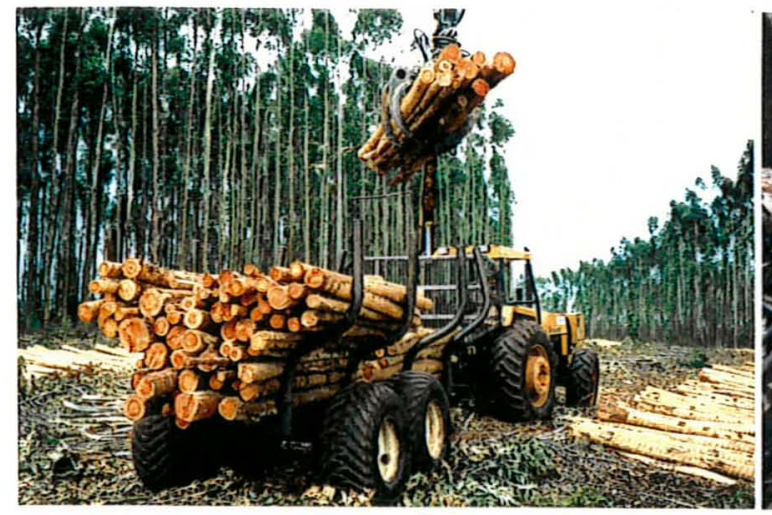

(a)

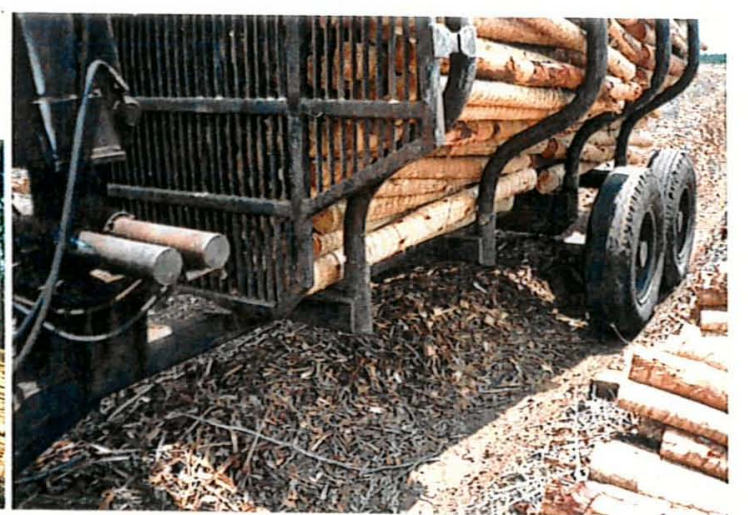

(b)

Figura 3: Carreta com pneus largos (a) e detalhe com pneus estreitos (b) 


\subsubsection{Amostragem}

Foram coletadas amostras não deformadas de solo com um martelo AMS e anéis metálicos de $50,8 \mathrm{~mm}$ (2") de diâmetro por $50,8 \mathrm{~mm}$ (2") de altura. Para cada parcela foram obtidas vinte (20) amostras para densidade, sendo dez (10) no rastro direito do trator e outras dez no rastro esquerdo, sendo cinco (5) amostras na primeira camada de 5 a $10 \mathrm{~cm}$ de profundidade e outras cinco na segunda camada de 12,5 a $17,5 \mathrm{~cm}$ de profundidade.
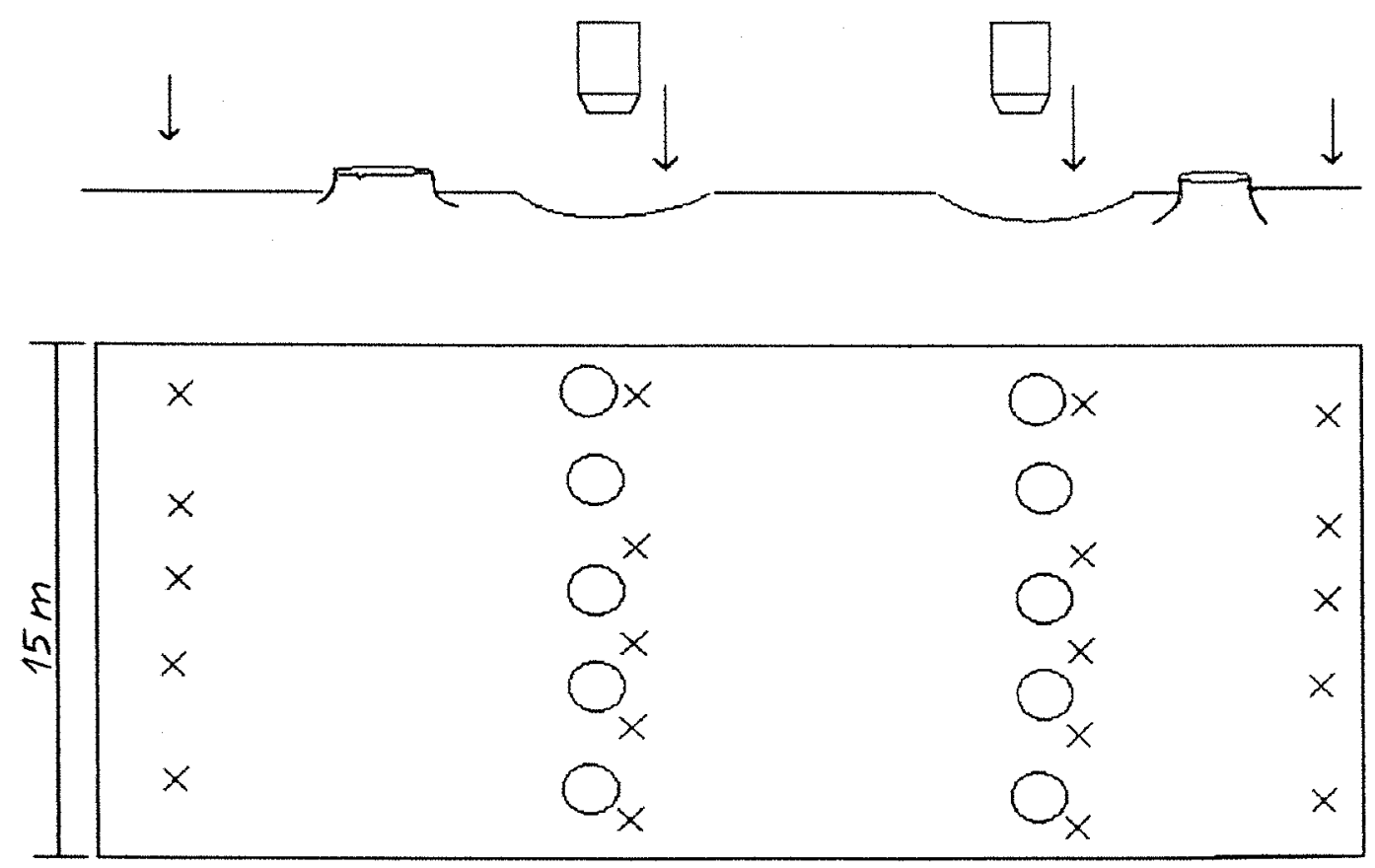

Figura 4: Representação esquemática dos locais de amostragem para índice de cone $(x)$ e densidade $(O)$.

A partir dessas amostras foram determinadas a composição granulométrica, densidade de partículas, densidade do solo, teor de água e porosidade estimadas segundo metodologia apresentada pela Embrapa (1979). As variáveis densidade e teor de água do solo consideradas, foram analisadas a partir de coletas em duas situações distintas sendo a primeira antes da colheita e a segunda após o tráfego para retirada de toda madeira.

Os tratamentos foram os seguintes: 
- Tratamento "A" (pneu estreito), onde o equipamento realizou toda a remoção equipado com pneus estreitos (11.00 - 22") calibrados a $455 \mathrm{kPa}(65 \mathrm{psi})$

- Tratamento "B" (pneu largo I), foi realizada a troca dos rodados. por aqueles montados com pneus mais largos (500/50-22.5") e calibrados a de $154 \mathrm{kPa}$ (22 psi).

- Tratamento "B" (pneu largo II), os pneus mais largos foram novamente calibrados, agora na pressão de $112 \mathrm{kPa}$ (16 psi) para trabalharem nos demais eitos

Ao remover a madeira do eito, os operadores anotaram o número de viagens realizadas e o volume de madeira transportado.

3.2.3 Densidade de partículas $\left(\rho_{p}\right)$, foi obtida pelo método de Blake \& Hartge (1986), que utiliza o picnômetro e cerca de 12 a $20 \mathrm{~g}$ de solo, seguindo-se várias pesagens.

3.2.4 Teor de água $(U)$, é a relação entre a massa de água contida numa amostra, sobre a massa de solo. $U$ é o teor de água do solo estimado e usualmente expresso em porcentagem.

A determinação da massa seca foi feita colocando-se as amostras em estufa a $105^{\circ} \mathrm{C}\left( \pm 2^{\circ} \mathrm{C}\right)$ por $24 \mathrm{~h}$. 
3.2.5 Densidade do solo $\left(\rho_{s}\right)$, é dado pela relação da massa seca de solo (PS), pelo volume contido no anel metálico $\left(V_{a}=81,54 \mathrm{~cm}^{3}\right)$.

3.2.6 Porosidade (P). com a determinação da densidade de partículas e densidade aparente do solo foi possivel obter a porosidade.

\subsection{7 Índice de Cone (IC)}

A resistência à penetração do solo foi estimada pelo indice de cone (IC) a partir das leituras obtidas com um penetrômetro de impacto até à profundidade de $50 \mathrm{~cm}$, transformando-se o número de impactos do penetrômetro ao longo do perfil do solo para força por unidade de área (MPa), por meio da fórmula dos holandeses utilizado por Stolf (1990) como segue:

IC $=0,0981^{\star}\left(5,6+6,89^{\star} n\right)$

sendo:

$n=\left(\frac{\text { impactos }}{d m}\right)$

As coletas de dados com o penetrômetro de impacto foram feitas próximo ao local onde foram coletadas as amostras com anéis metálicos, após o tráfego, no rastro do equipamento e comparado com o obtido na rua ao lado (sem tráfego). Este procedimento foi adotado para permitir a avaliação do índice de cone num mesmo teor de água do solo, visto ter ocorrido precipitações no periodo entre as amostragens pré e pós colheita. 


\subsection{Instalação do experimento}

A instalação foi casualizada com total de nove parcelas, três por tratamento, feita conforme as marcações nos "eitos" de corte como descrito no item 3.2.1, tendo-se a seguinte cronologia:

Primeiramente foram selecionados os eitos de corte com comprimento médio de $350 \mathrm{~m}$, mesma declividade e tipo de solo para o sorteio das parcelas definindo-se em qual delas o equipamento iria trabalhar de acordo com o estabelecido nos tratamentos.

A seguir foi feita a primeira fase da coleta das amostras em todas as parcelas, correspondente à condição sem tráfego antes da colheita.

Para a segunda fase, após as árvores terem sido cortadas e descascadas, iniciou-se com a explicação para os operadores dos procedimentos para a retirada da madeira com a carreta equipada com os pneus de acordo com os tratamentos citados em 3.2.2.

$\mathrm{Na}$ terceira e última fase foram coletadas as amostras para densidade e resistência à penetração, após ter sido retirada toda a madeira, que corresponde à segunda condição, após o tráfego.

Os valores da variável densidade do solo foram analisados pelo incremento ocorrido entre a situação inicial, antes da colheita e a situação final, após a colheita da madeira. A partir destas diferenças, 0 incremento de densidade foi comparado pelo teste " $F$ ". Havendo diferenças entre tratamentos, procedeu-se à comparação múltipla pelo teste de "Tukey", comparando-se média a média.

Para os valores de índice de cone os valores foram comparados com aqueles obtidos na linha não trafegada, e entre tratamentos pelo teste de "Tukey" a cada $2 \mathrm{~cm}$ de profundidade. A análise estatística foi realizada utilizando-se programa "SigmaStat for Windows". 


\section{RESULTADOS E DISCUSSÃO}

A estimativa da pressão média de contato foi feita a partir da Fórmula (1) e apresentada na Tabela 1, de acordo com Wasterlund (1994) como segue:

$$
P C=\frac{W}{r * l}
$$

sendo:

$\mathrm{PC}$ : pressão média de contato solo/pneu $(\mathrm{kPa})$;

W: carga aplicada por eixo $(\mathrm{kN})$;

$r$ : raio do pneumático $(m)$ e

1 : largura do pneumático $(\mathrm{m})$.

Segundo o fabricante, o peso da carreta é $20000 \mathrm{~N}$, e a carga que a carreta transporta é de 12 st de madeira, tendo-se que a madeira pesa em média $5500 \mathrm{~N} / \mathrm{st}$, tem-se uma carga de $86000 \mathrm{~N}$, distribuída em quatro pneumáticos, $\frac{86000}{4}=21500 \mathrm{~N} /$ pneumático.

Tabela 1: Pressão média de contato para cada tipo de pneu

\begin{tabular}{cccc}
\hline Tipo de pneu & $\mathrm{I}(\mathrm{m})$ & $\mathrm{r}(\mathrm{m})$ & $\mathrm{Pc}(\mathrm{kPa})$ \\
\hline Estreito $11.00-22^{\prime \prime}$ & 0,20 & 0,55 & 195 \\
Largo $500 / 50 \times 22,5$ & 0,50 & 0,49 & 88 \\
\hline
\end{tabular}

De acordo com a tabela acima nota-se que a pressão média de contato do pneu estreito sobre o solo foi duas vezes maior que aquela do pneu largo 
Verifica-se portanto, que o pneu estreito neste estudo está muito acima do permitido e o pneu largo é o que mais se aproxima da pressão de contato 35 a $60 \mathrm{kPa}$ recomendada por alguns autores. (Mellgren \& Heidersdorf, 1984 e Wasterlund, 1994).

A freqüência média de tráfego foi de 15 (quinze) viagens por eito em todos os tratamentos. O teor médio de água do solo na ocasião da operação era de $8,4 \%$

\subsection{Densidade}

\subsubsection{Densidade de partículas}

Os valores médios de densidade de partículas deste solo não apresentaram grandes variações, pois trata-se de uma característica vinculada à granulometria, como pode ser observado na Tabela 2.

Tabela 2: Densidade de partículas $\left(\mathrm{g} / \mathrm{cm}^{3}\right)$ para o solo local do experimento.

\begin{tabular}{cccccc}
\hline Picnômetro & Pic seco $(\mathrm{g})$ & Pic $\mathrm{H}_{2} \mathrm{O}(\mathrm{g})$ & Solo $(\mathrm{g})$ & $\mathrm{Pic}_{2} \mathrm{O}+$ solo $(\mathrm{g})$ & $\begin{array}{c}\text { Densidade } \\
\left(\mathrm{g} / \mathrm{cm}^{3}\right)\end{array}$ \\
\hline 1 & 37,22 & 101,18 & 17,65 & 112,14 & 2,6383 \\
2 & 38,71 & 101,75 & 14,73 & 110,89 & 2,6351 \\
3 & 38,43 & 100,08 & 17,97 & 111,22 & 2,6310 \\
4 & 35,67 & 99,63 & 16,55 & 109,89 & 2,6312 \\
5 & 35,62 & 98,24 & 18,44 & 109,64 & 2,6193 \\
6 & 34,81 & 98,29 & 16,17 & 108,31 & 2,6293 \\
Desvio & & & & & 0,0065 \\
Média & & & & 2,6307 \\
\hline
\end{tabular}

Fonte: Laboratório física do solo / Setor Irrigação e Drenagem / ESALQ / USP 


\subsubsection{Densidade do solo}

A diferença de densidade do solo entre os tratamentos foram analisadas individualmente e são apresentadas a seguir para cada uma das camadas estudadas.

Houve uma maior variabilidade no incremento da densidade do solo se comparada a primeira com a segunda camada, como pode ser observado nas Tabelas 3 e 6 . Esta diferença do grau de heterogeneidade reflete a variação natural do solo ao longo do perfil.

Tabela 3: Média e desvio padrão dos incrementos de densidade na camada de 5 a $10 \mathrm{~cm}$.

\begin{tabular}{ccc}
\hline Tratamento & Média & Desvio Padrão \\
\hline A & 0.13 & 0.103 \\
B & 0.06 & 0.075 \\
C & 0.12 & 0.113 \\
\hline
\end{tabular}

valores expressos em $\mathrm{g} / \mathrm{cm}^{3}$

A análise de variância apresentada na Tabela 4, refere-se ao incremento de densidade do solo para os três tratamentos na primeira camada. Verificou-se que houve diferenças estatisticamente significativas pelo teste $\mathrm{F}$ ao nivel de $5 \%$ de significância.

Tabela 4: ANOVA para o incremento de densidade na camada de 5 a $10 \mathrm{~cm}$.

\begin{tabular}{lccccc}
\hline Causas de variação & GL & SQ & QM & $E(Q M)$ & $F$ \\
\hline Tratamentos & 2 & 0.0692 & 0.0346 & 3.199 & 0.046 \\
Resíduo & 87 & 0.941 & 0.0108 & & \\
Total & 89 & 1.011 & & & \\
\hline
\end{tabular}


$\mathrm{Na}$ Tabela 5 são apresentados os valores e incrementos médios de densidade e a comparação múltipla feita pelo teste de Tukey.

Tabela 5: Valores e incrementos médios de densidade para a camada de 5 a $10 \mathrm{~cm}$

\begin{tabular}{cccc}
\hline Camada & $\begin{array}{c}\text { Pneu estreito } \\
455 \mathrm{kPa}\end{array}$ & $\begin{array}{c}\text { Pneu largo } \\
154 \mathrm{kPa}\end{array}$ & $\begin{array}{c}\text { Pneu largo } \\
112 \mathrm{kPa}\end{array}$ \\
\hline Densidade antes $^{*}$ & 1,65 & 1,69 & 1,67 \\
Densidade após $^{*}$ & 1,78 & 1,75 & 1,79 \\
Incremento* $^{*}$ & $0,13^{(\hat{a})}$ & $0,06^{(\mathrm{b})}$ & $0,12^{(\mathrm{ab})}$ \\
\% de incremento & 8,4 & 3,8 & 7,9 \\
\hline
\end{tabular}

* valores de densidade do solo em $\left(g / \mathrm{cm}^{3}\right)$, com mesma letra não diferem estatisticamente $(P<0,05)$

Para a camada de 5 a $10 \mathrm{~cm}$ de profundidade detectaram-se diferenças significativas estatisticamente. Verificou-se que a carreta equipada com pneus estreitos produziu o maior incremento na densidade do solo, mas em função principalmente da maior heterogeneidade encontrada nesta primeira camada, e pelas condições do teor de água do solo em estudo, não foi possivel relacionar com a pressão dos pneus largos. De acordo com Koger et al., (1983), a densidade do solo foi significativamente influenciada pela pressão dos pneus, mas em $25 \%$ dos casos não houve diferenças significativas.

Analisando-se a camada de 12,5 a $17,5 \mathrm{~cm}$ de profundidade, concluise que houve menor incremento e que o desvio padrão foi menor (Tabela 6). Também foram detectadas diferenças significativas entre os tratamentos de acordo com a análise de variância na Tabela 7 .

Tabela 6: Média e desvio padrão dos incrementos de densidade na camada 12,5 a $17,5 \mathrm{~cm}$.

\begin{tabular}{ccc}
\hline Tratamento & Média & Desvio Padrão \\
\hline A & 0.04 & 0.05 \\
B & -0.02 & 0.07 \\
C & -0.00 & 0.05 \\
\hline
\end{tabular}

valores expressos $\mathrm{em} \mathrm{g} / \mathrm{cm}^{3}$ 
Tabela 7: ANOVA para o incremento de densidade na camada de 12,5 a $17,5 \mathrm{~cm}$.

\begin{tabular}{lccccc}
\hline Causas de variação & GL & SQ & QM & E(QM) & F \\
\hline Tratamentos & 2 & 0.0631 & 0.0316 & 8.281 & $<0.001$ \\
Resíduo & 87 & 0.332 & 0.00381 & & \\
Total & 89 & 0.395 & & & \\
\hline
\end{tabular}

Para esta camada conclui-se que os apenas o pneu estreito produziu um incremento significativo na densidade como apresentado na Tabela 8.

Tabela 8: Valores e incrementos médios de densidade do solo para a camada de 12,5 a $17,5 \mathrm{~cm}$.

\begin{tabular}{cccc}
\hline $\begin{array}{c}\text { Camada } \\
12,5 \text { a } 17,5 \mathrm{~cm}\end{array}$ & $\begin{array}{c}\text { Pneu estreito } \\
455 \mathrm{kPa}\end{array}$ & $\begin{array}{c}\text { Pneu largo à } \\
154 \mathrm{kPa}\end{array}$ & $\begin{array}{c}\text { Pneu largo à } \\
112 \mathrm{kPa}\end{array}$ \\
\hline Densidade antes & 1,73 & 1,73 & 1,73 \\
Densidade após* & 1,77 & 1,71 & 1,73 \\
Incremento $^{*}$ & $0,04^{(\mathrm{a})}$ & $-0,02^{(\mathrm{b})}$ & $0,00^{(\mathrm{b})}$ \\
\% de incremento & 2,6 & -- &.- \\
\hline * valores de densidade do solo em $\left(\mathrm{g} / \mathrm{cm}^{3}\right)$, com mesma letra não diferem estatisticamente $(\mathrm{P}<0,05)$
\end{tabular}

Nota-se na tabela acima o valor negativo no incremento da densidade do solo, obtidos entre a condição inicial e final. De acordo com Reaves \& Cooper (1960), estes ocorrem com freqüência decorrente da condição não uniforme do solo.

Dentre os pneus mais largos nesta camada, também não houve diferença alguma em termos estatísticos para os incrementos de densidade. Neste caso, devido ao baixo teor de água no solo aliado a menor influência da pressão de contato em profundidade, não foi possivel detectar possiveis diferenças devido a pressão de inflagem nos pneus largos. 
Os resultados estão de acordo com Aust et al. (1993), que em seu estudo não encontraram interação entre largura de pneus e densidade. Os autores verificaram a dificuldade de relacionar largura de pneus com valores de densidade, mas pneus estreitos tiveram médias de densidade superiores como verificado neste estudo.

Em condições semelhantes, Seixas et al. (1998) constataram incrementos de densidade do solo da ordem de $19 \%$ para a camada de 12,5 a $17,5 \mathrm{~cm}$ de profundidade e $27 \%$ na camada de 5 a $10 \mathrm{~cm}$ de profundidade.

Segundo Soane et al. (1981), a porcentagem de incremento está associada com a densidade inicial do solo e sua resistência. Solos soltos terão maiores incrementos de densidade do que em solos firmes.

\subsection{Porosidade Total}

As maiores reduções de porosidade foram detectadas na camada mais superficial, verificando-se pequena alteração em subsuperfície, tendose também valores negativos que representam um acréscimo de poros. No entanto é mais provável que estes valores estejam em função da variabilidade do solo e não representam alterações relevantes (Tabela 9).

Tabela 9: Variações de porosidade ocorridas nos diferentes tratamentos

\begin{tabular}{clccc}
\hline Perfil estudado & \multicolumn{1}{c}{ Dados } & \multicolumn{3}{c}{ Tratamento } \\
\hline \multirow{3}{*}{5 a $10 \mathrm{~cm}$ profundidade } & p. estreito & p. largo I & p. largo II \\
& Média de Poros antes & 0,37 & 0,36 & 0,37 \\
& Média de Poros após & 0,32 & 0,33 & 0,32 \\
& Média de \% redução & 13,02 & 6,49 & 12,07 \\
\multirow{2}{*}{12,5 a 17,5 cm profundidade } & Média de Poros antes & 0,34 & 0,34 & 0,34 \\
& Média de Poros após & 0,33 & 0,35 & 0,34 \\
& Média de \% redução & 4,59 & $-2,79$ & $-0,51$ \\
\hline
\end{tabular}

Os valores da redução de porosidade foram proporcionais aqueles do incremento de densidade, como verificado no estudo feito por Seixas et al. (1998), refletindo o mesmo impacto desfavorável devido ao tráfego sem a presença da cobertura de resíduos. 


\section{3 Índice de Cone}

As leituras de índice de cone foram obtidos na condição média para teor de água do solo de $8,4 \%$.

A Figura 4 mostra as curvas médias de índice de cone, nos diferentes locais de amostragem, de acordo com os tratamentos, sendo:

Tratamento " $A$ "; curva para pneu estreito a $455 \mathrm{kPa}$ (65 psi),

Tratamento "B"; curva para pneu largo "I" a 154 kPa (22 psi),

Tratamento "C"; curva para pneu largo "II" a 112 kPa (16 psi) e

Tratamento "D"; curva para testemunha sem tráfego.

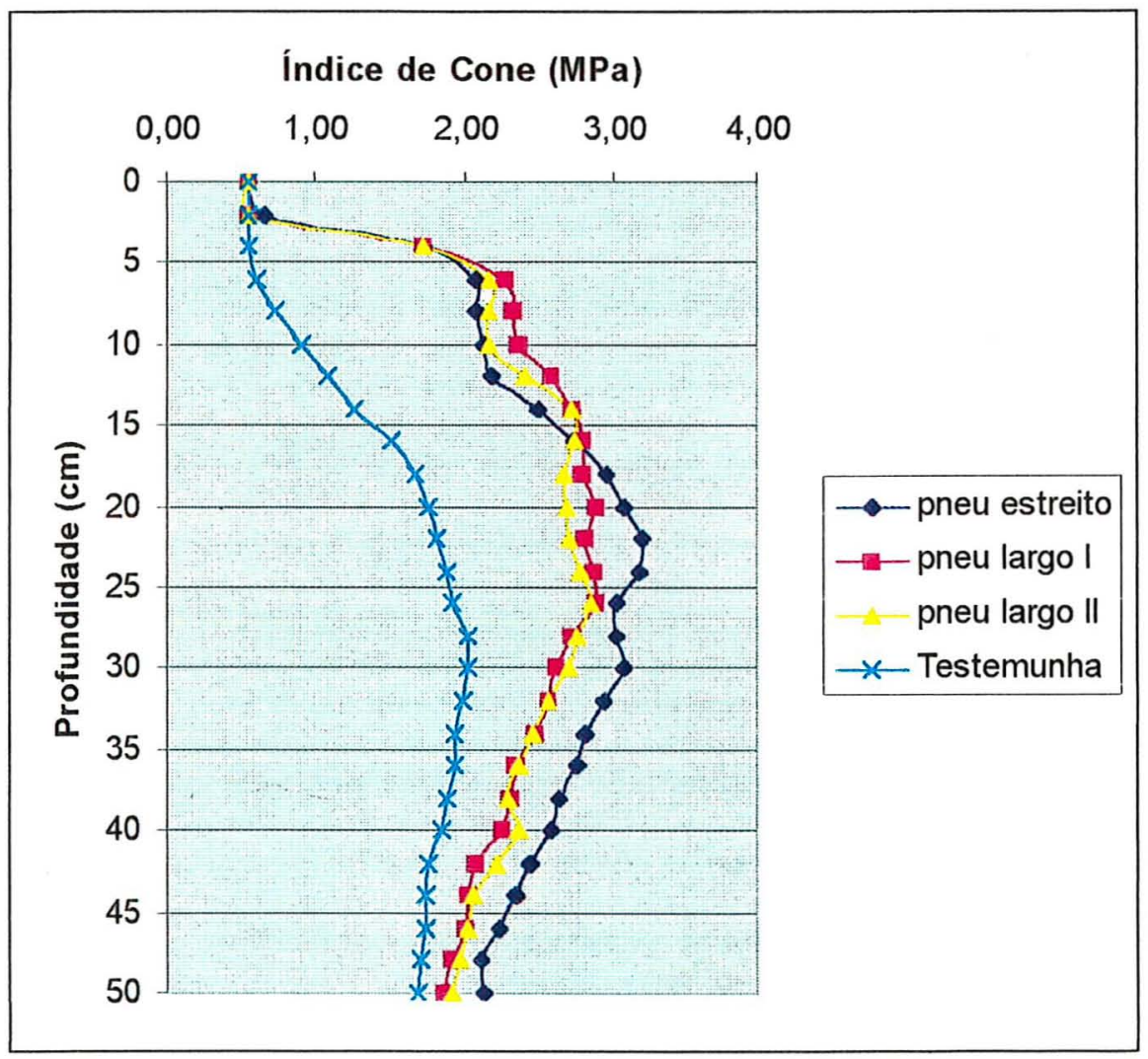

Figura 4: Curvas médias de índice de cone para os tratamentos. 
Nas condições de estudo as maiores variações de índice de cone ocorreram na camada de 0 a $10 \mathrm{~cm}$ de profundidade, as quais são apresentadas pela diferença entre os tratamentos em relação à testemunha como mostra a Figura 5.

Esta variação para os tratamentos na profundidade de 6 a $10 \mathrm{~cm}$ apresentaram valores de até $270 \%$, no entanto, não houve diferença estatisticamente significativa (Tabela 10), assim como para os valores de densidade, esta camada apresentou um maior grau de heterogeneidade.

Os dados estão de acordo com Upadhyaya \& Lanças (1994), o qual detectou que a magnitude dos valores de índice de cone variou em $326 \%$.

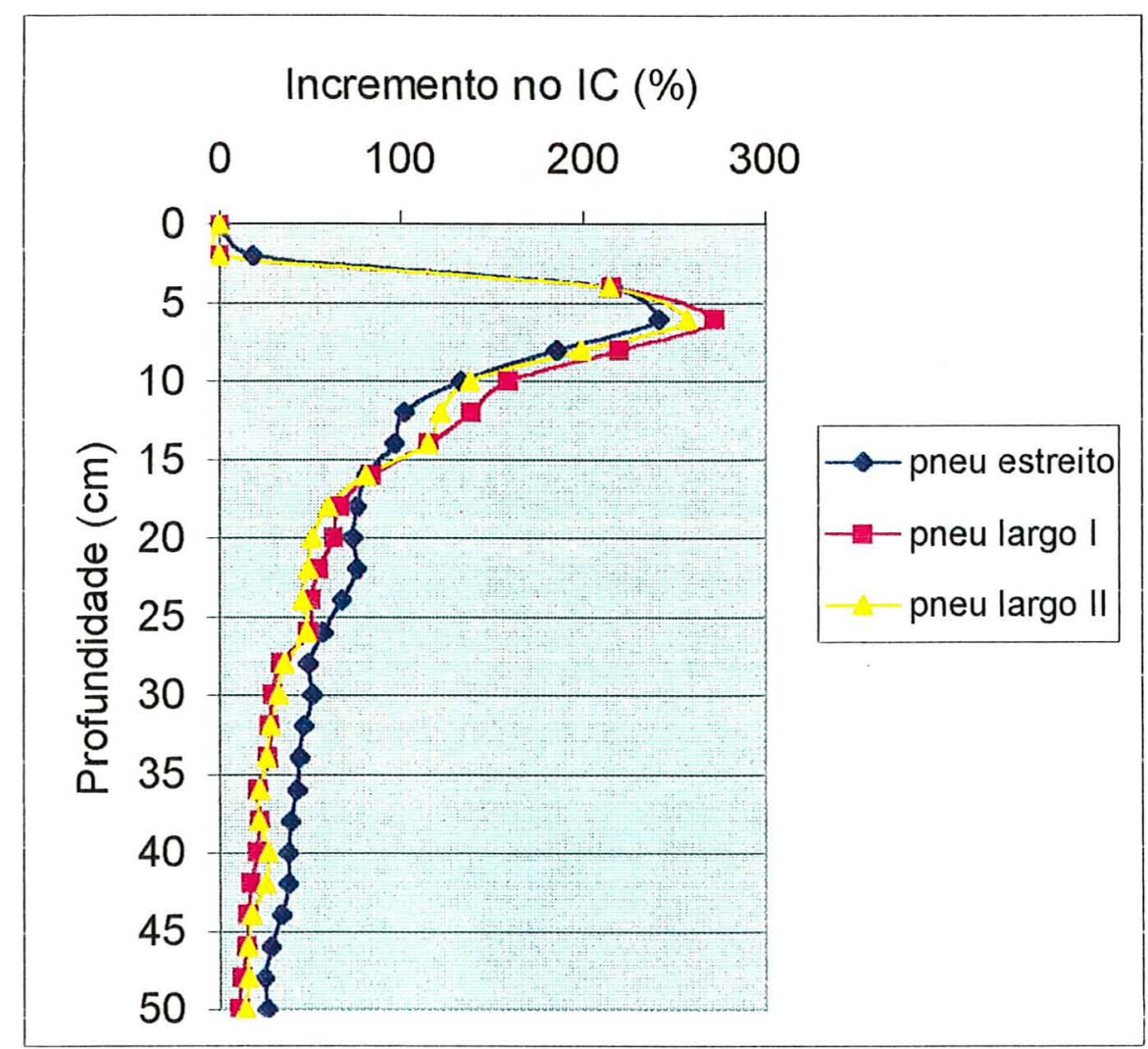

Figura 5: Variação porcentual dos tratamentos em relação à testemunha. 
No entanto, verificou-se pela análise de variância, que nas camadas subsuperficiais, onde há uma maior homogeneidade do solo, houve diferença significativa entre pneu estreito e largo, mas entre os pneus largos não foi detectado diferença significativa.

De acordo com Froehlich et al. (1980), nos estudos de compactação é melhor considerar os valores obtidos na faixa dos $20 \mathrm{~cm}$ de profundidade, por se tratar da região mais explorada pelo desenvolvimento radicular.

Gent et al. (1983) detectaram que após o corte das árvores, o tráfego das máquinas causou alteração mais pronunciada nas propriedades físicas na camada de 17 a $22 \mathrm{~cm}$ de profundidade.

Analisando-se as camadas em estudo, os dados de resistência à penetração estão em acordo com os obtidos de densidade. Pelas diferenças encontradas nas duas camadas estudadas em termos de variabilidade, sugere-se que os estudos nesta área podem ser mais representativos, se os parâmetros considerados forem obtidos a partir de profundidades $10 \mathrm{~cm}$ abaixo da superfície.

Para os pneus estreitos, detectou-se valores de indice de cone superiores a 3,00 MPa, no entanto todos apresentaram valores de índice de cone acima do limite de $2,50 \mathrm{MPa}\left(25 \mathrm{kgf} / \mathrm{cm}^{2}\right)$ considerado por Greacen \& Sands (1980) como crítico ao desenvolvimento radicular das principais espécies florestais.

Sendo assim, verificou-se que nas condições do estudo para os valores de índice de cone, o tráfego da carreta produziu compactação do solo tanto para pneus estreitos quanto para pneus largos.

A Tabela 10 a seguir mostra os valores da análise de variância para índice de cone e as diferenças analisadas para cada camada pelo teste de Tukey. 
Tabela 10: Diferenças de IC entre tratamentos.

\begin{tabular}{ccccc}
\hline Prof. & Estreito & Largo I & Largo II & Testemunha \\
\hline 2 a 4 & a & b & b & c \\
4 a 6 & a & b & b & c \\
6 a 8 & a & a & a & c \\
8 a 10 & a & a & a & c \\
10 a 12 & a & b & a & c \\
12 a 14 & a & a & a & c \\
14 a 16 & a & a & a & c \\
16 a 18 & a & ab & b & c \\
18 a 20 & a & ab & b & c \\
20 a 22 & a & b & b & c \\
22 a 24 & a & b & b & c \\
24 a 26 & a & a & a & c \\
26 a 28 & a & a & a & c \\
28 a 30 & a & b & ab & c \\
30 a 32 & a & b & b & c \\
32 a 34 & a & ab & b & c \\
34 a 36 & a & b & b & c \\
36 a 38 & a & b & b & c \\
38 a 40 & a & b & ab & c \\
40 a 42 & a & b & ab & c \\
42 a 44 & a & b & b & c \\
44 a 46 & a & a & a & c \\
46 a 48 & a & a & a & c \\
48 a 50 & a & bc & b & c
\end{tabular}

Letras iguais não diferem estatisticamente ao nível de $5 \%$

Os dados obtidos mostram uma tendência de maior compactação para o pneu estreito, em relação às demais curvas na profundidade 20 a 24 $\mathrm{cm}$. Pela análise estatística, nesta camada houve diferenças significativas mais pronunciadas. É nessa profundidade que segundo alguns autores, há uma intensificação das forças que atuam no solo (Koger et al., 1983 e Taylor et al., 1980 e 1989). 


\section{CONCLUSÕES}

Verificou-se que em termos de incremento de densidade e índice de cone a magnitude dos danos produzidos pelo tráfego da carreta foram mais pronunciados na camada de 5 a $10 \mathrm{~cm}$ de profundidade.

Considerando-se o baixo teor de água no solo na ocasião do experimento foi possivel constatar redução da compactação na primeira camada apenas para o pneu largo inflado a $154 \mathrm{kPa}$.

Para a camada de 12,5 a $17,5 \mathrm{~cm}$ de profundidade apenas o pneu estreito causou incremento na densidade do solo.

Em termos de variação do índice de cone registraram-se valores que refletem uma compactação nas áreas trafegadas com o pneu estreito, em relação ao pneu largo, com diferenças mais pronunciadas somente a partir de $18 \mathrm{~cm}$ abaixo da superfície.

As pressões de inflagem testadas nos pneus largos não tiveram influência na compactação em nenhuma das camadas estudadas, muito provavelmente em decorrência do baixo teor de água no solo.

Verificou-se de modo geral que o pneu estreito, projetado para caminhões, é o menos indicado para a utilização em operações florestais dentro do talhão pelo potencial de danos que representa sua maior pressão de contato em relação ao pneu mais largo. 


\section{REFERÊNCIAS BIBLIOGRÁFICAS}

ADAM, K.M.; ERBACH, D.C. Relationship of tire sinkage depth to depth of soil compaction. Transactions of the ASAE, v.38, n.4, p.1011-1016, 1995.

AFFÉRRI, A.Z. Estimativa das condições de tráfego em solo agrícola. Piracicaba, 1992. 118p. Dissertação (Mestrado) - Escola Superior de Agricultura "Luiz de Queiroz", Universidade de São Paulo.

ALVARENGA, R.C. Produção de matéria seca e absorção de nutrientes por leguminosas, em resposta à compactação do solo. Revista Ceres, v.44, n.421-431, jul./ago. 1997.

ANUÁRIO ESTATISTICO BRASILEIRO - 1996, v.56, p.3. 66, 1996.

AUST, W.M.; REISINGER, T.W.; STOKES, B.J. et al. Tire performance as a function of width and number of passes on soil bulk density and porosity in a minor stream bottom. In: BIENNIAL SOUTHERN SILVICULTURAL RESEARCH CONFERENCE, 7., Mobile, 1992. Proceedings. New Orleans: USDA, Forest Service, Southern Forest Experiment Station, 1993. p. $137-141$. 
AUST, W.M.; TIPPETT, M.D.; BURGER, J.A.; et al. Compaction and ruting during harvesting affect better drained soils more than poorly drained soils on wet pine flats. Southern Journal of Applied Forestry, v.19, n.2, p. $72-77$, May 1995

AYERS, P.D.; PERUMPRAL, J.V. Moisture and density effect on cone index. Transactions of the ASAE, v.25, n.5, p.1169-1172, 1982.

BACHA, C.J.C.; PIZZOL, S.J.S. Evolução, estrutura e desafios da indústria de celulose no brasil. Preços Agrícolas, p.3-13, mar. 1998.

BAILEY, A.C.; RAPER, R.L.; BURT, E.C. The effects of tire pressure on soil stresses. St Joseph: ASAE, 1991. 11p. (ASAE. Paper, 91-1062)

BAILEY, A.C.; RAPER, R.L.; WAY, T.R. et al. Soil stresses under tractor tires at various inflation pressures. Alabama Experiment Station Journal, v.2, 10p. 1993. (Paper, 93-3483)

BALASTREIRE, L.A. Máquinas agrícolas. São Paulo: Manole, 1987. 310p.

BARROS, N.F.; NOVAIS, R.S. Relação solo-eucalipto. Viçosa: 1990. $330 p$.

BÉDARD, Y.; TESSIER. S.; LAGUË, C. et al. Soil Compaction by manure spreaders equipped with standard and oversized tires and multiple axles. Transactions of the ASAE, v.40, n.1, p.37-43, 1997.

BEKKER, G.M. Off the road locomotion. Ann Arbor: University of Michigan Press, 1960. $220 \mathrm{p}$. 
BLAKE, G.R.; HARTGE, K.H. Bulk density. In: KLUTE, A. (Ed). Methods of soil analysis. 2. ed. Madison: American Society of Agronomy, 1986. p.363-382. (Agronomy 9).

BODMAN, G.B.; CONSTANTIN, G.K. Influence of particle size distribution in soil compaction. Hilgardia, v.36, p.567-591. 1965.

BURGER, J.A.; WIMME,K.J.; STUART,W.B. Site disturbance and machine performance from tree - length skidding with a rubber - tire skidder. In: BIENNIAL SOUTHERN SILVICULTURAL RESEARCH CONFERENCE, 5., Memphis, 1988. Proceedings.

BURT, E.C.; LYNE, P.W.L.; MEIRING, P.; KEEN, J.F. Ballast and inflation pressure effects on tractive efficiency. St Joseph: ASAE, 1982. 7p. (ASAE. Paper, 82-1567)

BURT, E.C.; WOOD, R.K.; BAILEY, A.C. Some comparations of average to peak soil - tire contact pressures. St Joseph: ASAE, 1990. 10p. (ASAE. Paper, $90-1094$ ).

CAMARGO, M.N.; KLANT,E.; KAUFFMAN,J.H. Classificação de solos usada em levantamentos pedológicos no Brasil. Boletim Informativo Sociedade Brasileira de Ciências do Solo, v.12, p.11-13, 1987.

CARTER, L.M.; TRAVERNETTI, J.R. Influence of precision tillage and soil compaction on cotton yields. Transactions of the ASAE, v.11, n.1, p.65- 73, Jan. / Feb. 1968.

CHANCELLOR, W.J. Compaction of soil by agricultural equipment. Davis: University of California, 1977. 53p. (Bulletin, 1881). 
COLETI, J.T.; DEMATTÊ, J.L.I. Compactação artificial em solos experiência e dados informativos. Álcool e Açúcar, v.2, n.6, p.34-39, set. / out. 1982.

DANIEL, E.L. Tráfego controlado em parcelas motomecanizadas: avaliação preliminar da resistência do solo à penetração. In: CONGRESSO BRASILEIRO DE ENGENHARIA AGRICOLA, 22., Campinas, 1993. Anais. Campinas: SBEA, 1993. v.2, p. $2090-2101$.

DAVIS, G.R.; NEILSEN, W.A.; McDAVITT, J.G. Root distribution of Pinus radiata related to soil characteristics in five Tansmanian soils. Australian Forest Research. v.21, p.165-171, 1983.

DWYER, M.J.; HEIGO, D.P. The tractive performance of some large drive wheel tyres compared with dual wheels. Journal of Agricultural Enginering Research, v. 29, p. 43-50, 1984.

EKWUE, E.I.; STONE, R.J. Organic matter effects on the strength properties of compacted agricultural soils. Transactions of the ASAE, v. 38, n.2, p. $357-365,1995$

EMPRESA BRASILEIRA DE PESQUISA AGROPECUÁRIA. Serviço Nacional de Levantamento e Conservação de Solo. Manual de métodos de análise do solo. Rio de Janeiro, 1979. $1 \mathrm{v}$.

ERBACH, D.C.; KNOLL, K.K. Inflation pressure effect on soil compaction. St Joseph: ASAE, 1992. 13 p. (ASAE. Paper, 92-1582). 
FENNER, P.T. Relações entre tráfego de veículos e as deformações físicas dos solos. In: SEMINÁRIO DE ATUALIZAÇÃO SOBRE SISTEMAS DE COLHEITA DE MADEIRA E TRANSPORTE FLORESTAL, 9., Curitiba, 1996. Anais. Curitiba: Fundação de Pesquisas Florestais do Paraná, 1996, p. 39-43.

FERNANDES, B.; GALLOWAY, H.M. Efeito das rodas do trator em propriedades físicas de dois solos. Revista Ceres, v.34, n.196, p.562$568,1987$.

FOLTZ, R.B.; BURROUGHS, E.R.,JR. A test of normal tire pressures and reduced tire pressure on forest roads: Sediment effects. In: FORESTRY AND ENVIRONMENT, ENGINEERING SOLUTIONS CONFERENCE, New Orleans, 1991. Proceedings. St. Joseph: ASAE, 1991. (ASAE. Publications, 09-91).

FROEHLICH, H.A. Soil compaction: Why the controversy? Logger Handbook, v.37, p.20-22, 1977.

FROEHLICH, H.A. Predicting soil compaction on forested land. Corvallis: Oregon State University, Forest Engineering Department, 1980. 120p. (Final Project Report to U.S. Forest Service).

FROEHLICH, H.A.; McNABB, D.H. Minimizing soil compaction in pacific northwest forests. In: NORTH AMERICAN FOREST SOILS CONFERENCE ON FOREST SOILS AND TREATMENT IMPACTS, 6. Knoxville, 1983. Proceedings. p.159-192. 
GENT JR, J.A.; BALLARD, R.; HASSAN, A.E. The impact of harvesting and site preparation on the physical properties of lower coastal plain forest soils. Soil Science Society of America Journal, v.47, p.595-598, 1983

GENT JR, J.A.; BALLARD, R. Impact of intensive forest management practices on the bulk density of lower coastal plain and Piedmont soils. Southern Journal of Appied Forestry, v.9, n.1, p.44 - 48, 1985.

GILL, W.R.; VANDEN BERG, G.E. Soil dynamics in tillage and traction. Washington: USDA, 1968. 511p. (Agricultural Handbook, 316).

GOLDSACK, R. Truck tyre pressures effects on truck and road. LIRA Report, v.13, n.8, p. 1-5, 1988.

GONÇALVES, J.L.M. Características do sistema radicular de absorção do Eucalyptus grandis sob diferentes condições edáficas. Piracicaba, 1994. 84p. Tese (Livre Docência) - Escola Superior de Agricultura "Luiz de Queiroz", Universidade de São Paulo.

GREACEN, E.L.; SANDS, R. Compaction of forest soils: a review. Australian Journal of Soil Research, v.18, p.163 - 189, 1980.

HAMMEL, K. Soil stress distribution under lugged tires. Soil \& Tillage Research, v. 32, n.2-3, p.163-181, 1994.

HATCHELL, G.E. Soil compaction and loosening treatments affect loblolly pine growth in pots. Asheville: USDA, Forest Service Research, 1970. 9p. (USDA. Forest Service Research. Paper SE, 72). 
HOWARD, R.F.; SINGER, M.J.; FRANTZ, G.A. Effects of soil properties, water content and comparative effort on the compaction of selected california forest and range soils. Soil Science Society of America Journal, v.45, p.2313-2316, 1981.

INCERTI, M.; CLINNIK, P.F.; WILLATT, S.T. Changes in the physical properties of a forest soil following logging. Australian Forestry Research, v.17, p.91-98, 1987.

JAKOBSEN, B.F. Persistence of compaction effects in a forest kraznozem. Australian Forest Research, v.13, p.305-308, 1983.

JONES, G.; SMITH, M. Central tyre Inflation the Unit States and New Zealand experience. LIRA Report, v.16, n.9, p.1-8, 1991.

KING, T.; HAINES, S. Soil compaction absent in plantation thinning. New Orleans: Southern Forest Experiment Station, 1979. 4p. (Research Note, SO - 251).

KLAAS, R.N. Forestry tire trends. In: COUNCIL ON FOREST ENGINEERING ANNUAL MEETING, Quebec, 1988. Proceedings. p. $27-30$.

KOGER, J.L.; BURT, E.C.; TROUSE, A.C. Multiple pass effects of skidder tires on soil compaction in soil bins. St. Joseph: ASAE, 1983. 19p. (ASAE. Paper, 83-1619). 
KREH, R.E.; BURGER, J.A.; TORBERT, J.L. Soil compaction from tracked and rubber-tired tractors and its influence on seedling survival and growth. In: SOUTHERN SILVICULTURAL RESEARCH CONFERENCE. Atlanta, 1984. Proceedings. p.327-330.

LANÇAS, K.P.; UPADHYAYA,S.K. Pneus radiais para tratores: guia para seleção correta da pressão de inflação. Energia na Agricultura Boletim Técnico, n.1, p.1-33, 1997.

LANGENAKENS, J.J. A model for measuring the effect of tire pressure and drive speed on horizontal sprayer boom movements and spray pattern. Transactions of the ASAE, v.38, n.1, p.65-72, 1995.

LIRA FILHO, J.A. Avaliação do impacto da exploração florestal no meio ambiente. In: SIMPÓSIO BRASILEIRO SOBRE EXPLORAÇÃO E TRANSPORTE FLORESTAL, Belo Horizonte, Anais. Belo Horizonte, 1990. p.94112.

LOCKABY, B.G.; VIDRINE, C.G. Effect of logging equipment traffic on soil density and growth and survival of young lobolly pine. Southern Journal of Appied Forestry, v.8, n.2, p.109-112, May 1984.

LYNE, P.W.; BURT, E.C.; MEIRING, P. Effect of tire and engine parameters on efficiency. Transactions of the ASAE, v.27, n.1, p.5-7, 1984.

MANTOVANI, E.C.; MARTYN, P.J.; BERTAUX, S. et al. Comparação do coeficiente de tração e da eficiência tratória de um trator agrícola obtidos pela equação de Wismer e Luth e por ensaios de campo. Pesquisa Agropecuária Brasileira, v.30, n.4, p.523-530, abr. 1995. 
McDONALD, T.P.; WAY, T.; SEIXAS, F. Soil compaction effects of forwarding with wide tires and tracks. St Joseph: ASAE, 1995. 8p. (ASAE. Paper, 95-7203).

MCDONALD, T.P.; WAY, T.; SEIXAS, F. et al. Load and inflation pressure effects on soil compaction of forwarder tires. In: JOINT CONFERENCE OF CANADIAN WOOD LANDS FORUM, Quebec, 1996. Proceedings. Montreal: IUFRO, 1996. p.E67-70.

MCKEE, W.H.; HASELTON, R.D. Managing site damage from logging: a loblolly pine management guide. Washington: USDA, Forest Service Southeastern Forest Experiment Station, 1985. 21p.

MCLEOD, H.E.; REED, I.F.; JOHNSON, W.H.; GILL, W.R. Draft, power efficiency, and soil-compaction characteristics of single, dual and lowpressure tires. Transactions of the ASAE, v.9, n.1, p.41-44, 1966.

MCMAHON, S.; EVANSON, T. The effect of slash cover in reducing soil compaction resulting from vehicle passage. LIRO Report, v.19, n.1, p. 18, 1994

MELLGREN, P.G.; HEIDERSDORF, E. The use of high flotation tires for skidding in wet and/or steep terrain. Alberta: Forest Engineering Research Institute of Canada, 1984. 48p. (FERIC. Tecnical Report, TR57).

MIALHE, L.G. Desempenho de tratores agricolas, com um e dois eixos propulsores, em terrenos cultivados. Piracicaba. 1980. 175p. Tese (Livre Docência) - Escola Superior de Agricultura "Luiz de Queiroz", Universidade de São Paulo. 
MIALHE, L.G.; RIPOLI, T.C.; MELO,I.S. Tratores de tração em quatro rodas. Estudo preliminar comparativo da tração em duas e quatro rodas. In: CONGRESSO SOCIEDADE BRASILEIRA DE ENGENHARIA AGRÍCOLA, 9., Campina Grande, 1980. Anais. Campina Grande, UFPb, 1980. v1, p238-254.

MIALHE, L.G. O estado da arte e perspectivas da utilização de rodados pneumáticos de baixa pressão na área agrícola. In: ENCONTRO SOBRE PNEUS DE ALTA FLUTUAÇÃO E BAIXA PRESSÃO NAS ÁREAS AGRíCOLA E FLORESTAL, Piracicaba, 1993. Piracicaba: ESALQ, 1993. p.1-17.

MILAN, M. Avaliação de desempenho de 4 modelos de pneumáticos agrícolas em solo de textura média. Piracicaba, 1986. 119p. Dissertação (Mestrado) - Escola Superior de Agricultura "Luiz de Queiroz", Universidade de São Paulo.

MILAN, M. Resistência ao rolamento em função da pressão de insuflagem do rodado dianteiro de um trator agrícola. In: SIMPÓSIO DE INICIAÇÃO CIENTÍfICA DA USP, Piracicaba, 1996. Resumos. São Paulo: USP, 1996. v.1, p.462.

NOVAK, R.K.; MANTOVANI,E.C.; MARTYN,P.J.; FERNANDES,B.; Efeito do tráfego de trator $e$ da pressão de contato pneu/solo na compactação de um latossolo vermelho - escuro álico, em dois níveis de umidade. Pesquisa Agropecuária Brasileira, v.27, n.12, p.1587-1595, dez. 1992.

OHU, J.O.; RAGHAVAN,G.S.V.; McKYES,E.; MEHUYS,G. Shear strength prediction of compacted soil with varying organic matter content. Transactions of the ASAE, v.29, n.2, p.351-355, 1986. 
PERUMPRAL, J.V. Cone penetrometer applications: a review. Transactions of the ASAE, v.30, n.4, p.939-944, July / Aug. 1987.

RAGHAVAN, G.S.V.; ALVO, P.; McKYES, E. Soil compaction in agriculture: a view toward managing the problem. Quebec: McGill University, Department of Agricultural Engineering, 1995. 36p.

RAPER, R.L.; BAILEY, A.L.; BURT, E.C. et al. Inflation pressure and dinamic load effects on soil deformation and soil-tire interface stresses. Transactions of the ASAE, v.38, n.3, p.685-689, 1995.

REAVES, C.A.; COOPER, A.W. Stress distribution in soil under tractor loads. Agricultural Engineering, v.41, n.1, p.20-31, Jan. 1960.

REISINGER, T.W.; POPE, P.E.; HAMMOND, S.C. Natural recovery of compacted soil in an upland hardwood forest in Indiana. North Journal of Applied Forestry, v.9, n.4, p.138-141, 1992.

RIPOLI, T.C.C. Subsolagem e subsoladores. Piracicaba: CALQ, 1985. $34 p$.

SANDS, R.; BOWEN, G.D. Compaction of sandy soils in radiata pine forests. Australian Forest Research, v.8, p.163-170, 1978.

SAUDER, B.J. Low ground pressure tires for skidders. Ottawa: Canadian Forestry Service, 1985. 24p. (Information Report, DPC $-X-20$ ).

SCHAFER, R.L.; JOHNSON, C.E.; KOOLEN, A.J. et al. Future research needs in soil compaction. Transactions of the ASAE, v.36, n.6, p.17611770, Nov. / Dec. 1992. 
SCHILLING, A. Tires and machines for sensitive logging. In: COUNCIL ON FOREST ENGINEERING ANNUAL MEETING, 16., Savannah, 1993. Proceedings. Savannah: University of Georgia, 1993.

SEIXAS, F.; McDONALD, T.P.; STOKES, B.J.; RAPER, R.L. Effect of slash on forwarder soil compaction. In: COUNCIL ON FOREST ENGINEERING ANNUAL MEETING, 18., Cashiers, 1995, p.77-86.

SEIXAS, F, Avaliação de impactos da colheita de madeira no solo. In: PROGRAMA DE RECICLAGEM EM MÉTODOS QUANTITATIVOS, 2 ., Piracicaba, 1996. Piracicaba: ESALQ; IPEF, 1996. 24p.

SEIXAS, F. Pneus: qual a adequada pressão de insuflagem? Piracicaba: IPEF, 1997. 4p. (IPEF. Circular Técnica, 185).

SEIXAS, F.; OLIVEIRA JR., E.D.; SOUZA, R.C. Efeito da camada de resíduos florestais na compactação do solo causada pelo transporte primário da madeira. IPEF, 1998. (No prelo)

SEIXAS, F. Exploração e transporte de Eucalyptus spp. Piracicaba: IPEF, 1987. 40p.

SMITH, B.E.; BURCHAM, T.N.; TO, F.S. et al. Mobile soil - tire interface measurement system. Transactions of the ASAE, v.37, n.5, p.1633$1637,1994$.

SOANE, B.D.; BLACKWELL, P.S.; DICKSON, J.W; PAINTER, D.J. Compaction by agricultural vehicles: a review II. Soil \& Tillage Research, v.1, p.373-400, 1981. 
SÖHNE, W. Fundamentals of pressure distribution and soil compaction under tractor tires. Agricultural Engineering, v.39, n.1, p.276-290, 1958 .

STOLF, R. Fórmulas de transformação dos dados de penetrômetro de impacto em força por unidade de área. In: CONGRESSO BRASILEIRO DE ENGENHARIA AGRÍCOLA, 19., Piracicaba, 1990. Anais. Piracicaba: SBEA, 1990. v.2, p.823-850.

STONE, R.J.; EKWUE, E.I. Maximum bulk density achieved during soil compaction as affected by the incorporation of three organic materials. Transactions of the ASAE, v.36, n.6, p.1713-1719, Nov. / Dec. 1993.

STRANSKY, J.J. Site preparation effects on soil bulk density and pine seedling growth. Southern Journal of Applied Forestry, v.5, n.4, p.176-180, 1981.

TAYLOR, J.H.; BURT, E.C. Pneumatic tracks for super traction? Agricultural Engineering, v.55, n.2, p.17-18, Feb. 1974.

TAYLOR, J.H.; BURT, E.C.; BAILEY, A.C. Radial tire performance in firm and soft soils. St Joseph: ASAE, 1976. 7p. (ASAE. Paper, 76-1036)

TAYLOR, J.H., TROUSE JR, A.C., BAILEY, A.C. et al. Multipass behavior of a pneumatic tire in tilled soils. St Joseph: ASAE, 1979. 9p. (ASAE. Paper, 79-1549)

TAYLOR, J.H., BURT, E.C., BAILEY, A.C. Effect of total load on subsurface soil compaction. Transactions of the ASAE, v.23, n.3, p.568 - 570, 1980. 
TAYLOR, J.H., BURT, E.C., BAILEY, A.C. Multipass behavior of a pneumatic tire in tilled soils. Transactions of the ASAE, v.25, p. $1229-1236,1982$.

TAYLOR, J.H.; BURT, E.C. Flotation tires and subsurface compaction. In: INTERNATIONAL CONFERENCE OF ISTVS, 8., Cambridge, 1984. Proceedings. v.2, p.752-759.

TAYLOR, J.H. ; BURT, E.C. ; MONROE, G.E. Effect of dualing tires on soil compaction. St Joseph: ASAE, 1989. 7p. (ASAE. Paper, 89-1052).

TUTTLE, C.L.; GOLDEN, M.S.; MELDAHL,R.S. Soil compaction effects on Pinus taeda establishment from seed and early growth. Canadian Journal of Forest Research, v. 18, p.628-632, 1988.

UNGER, P.W.; KASPAR, T.C. Soil compaction and root growth: a review. Agronomy Journal, v.86, n.5, p.759-766, 1994.

UPADHYAYA, S.K.; LANÇAS, K.P. How to get the most from radial ply tractor tyres: a guide to select the corrent inflation pressure. Davis: University of California, Biological and Agricultural Engineering Department, 1994. 29p.

VANDENBERG,G.E.; GILL,W.R. Pressure distribution between a smooth tire and the soil. Transactions of the ASAE, v.5, n.2, p.105-107, 1962.

VOMOCIL, J.A.; FLOCKER, W.J. Effect of soil compaction on storage and movement of soil air and water. Transaction of the ASAE, v. $4, n .2$, p.242-246, 1961. 
VOORHEES, W.B. Soil compacion: our newest natural resourse. Crops and Soils Magazine, v.29, n.5, p.13-15; n.6, p.7-10; n.7, p.11-13, 1977.

VOORHEES. W.B.; SENST, C.G.; NELSON, W.W. Compaction and soil structure modification by wheel traffic in the north corn belt. Soil Science Society of America Journal, v.42, n.2, p.344-349, Mar. / Abr. 1978.

WASTERLUND, I. Enviromentally soft machines. Small Scale Forestry, v.1, p.13-15, 1994

WAY, T.R.; BAILEY, A.C.; RAPER, R.L.; BURT, E.C. Tire lug height effect on soil stresses and bulk density. Transactions of the ASAE, v.38, n.3, p.669-674, 1995.

WAY, T.R.; KISHIMOTO, T.; BURT, E.C. et al. Tractor tire aspect ratio effects on soil stresses and rut depths. Transactions of the ASAE, v.40, n.4, p.871-881, 1997.

WOOD, R.K.; MAGIONE, D.A. Tractive benefits of properly adusted inflation pressures: farmers experiences. St Joseph: ASAE, 1992. 6p. (ASAE. Paper, 92-1583)

WOOD, R.K.; MORGAN, M.T.; HOLMES, R.G. et al. Soil physical properties as affected by traffic: single, dual and flotation tires. St Joseph: ASAE, 1990. 18p. (ASAE. Paper, 90 - 1550).

WRONSKI, E. Looging trials near tumut. Logger, p.10-14, Abr. / May 1990. 
WRONSKI, E; HUMPHREYS, N. A method for evaluating the cumulative impact of ground - based logging systems on soils. Journal of Forest Engineering, v.5, n.2, p.9-20, Jan. 1994.

YASIN, M.; GRISSO, R.D.; BASHFORD, L.L. et al. Normalizing cone resistance values by covariance analysis. Transactions of the ASAE, v.36, n.5, p.1267 - 1270, Sept. / Oct. 1993.

YONG, E.M. Wide tire versus conventional tire forwarders: two comparative studies, 1988 and 1990. Newfoundland: Forest Products and Development Division, 1992. 19p. (FPD. Report, 60). 